\title{
Review
}

Ting-Hsuan Lai, Ken-ichi Katsumata and Yung-Jung Hsu*

\section{In situ charge carrier dynamics of semiconductor nanostructures for advanced photoelectrochemical and photocatalytic applications}

https://doi.org/10.1515/nanoph-2020-0472

Received August 13, 2020; accepted October 14, 2020; published online November 16, 2020

\begin{abstract}
Using in situ ultrafast laser spectroscopic techniques to monitor the charge dynamics of semiconductor photocatalysts under operating conditions is essential for digging out the veritable interactions between charge carriers and the reactive species. This real-time observation is desirable for optimizing individual components and their integration in advanced photoelectrochemical (PEC) and photocatalytic systems, which can achieve the "Holy Grail" of solar energy harvesting and solar fuel generation. This Review summarizes the recent developments of employing transient absorption spectroscopy for in situ measurements of charge dynamics on semiconductor nanostructures. The implications in the PEC and photocatalytic reactions toward hydrogen production and carbon dioxide reduction will be discussed, along with future outlooks and perspectives.
\end{abstract}

Keywords: carbon dioxide reduction; hydrogen production; in situ; photocatalysis; transient absorption.

\footnotetext{
*Corresponding author: Yung-Jung Hsu, Department of Materials Science and Engineering, National Chiao Tung University, Hsinchu 30010, Taiwan; and Center for Emergent Functional Matter Science, National Chiao Tung University, Hsinchu 30010, Taiwan, E-mail: yhsu@cc.nctu.edu.tw

Ting-Hsuan Lai, Department of Materials Science and Engineering, National Chiao Tung University, Hsinchu 30010, Taiwan, E-mail: alan821012@gmail.com Ken-ichi Katsumata, Department of Materials Science and Technology, Faculty of Industrial Science and Technology, Tokyo University of Science, Tokyo 125-8585, Japan; and Photocatalysis International Research Center, Tokyo University of Science, Chiba 278-8510, Japan, E-mail: k.katsumata@rs.tus.ac.jp
}

\section{Introduction}

Over the past few decades, hundreds of thousands of accomplished scientists have dedicated themselves to finding a better energy source that can replace fossil fuels. Plenty of strategies toward the development of clean, sustainable energy resources have been proposed and realized, such as solar heat collection [1, 2], thermoelectric conversion [3, 4], photovoltaics [5, 6], water electrolysis $[7,8]$, solar hydrogen production $[9,10]$, and carbon dioxide reduction [11, 12]. A reliable and sustainable alternative energy source must be realized to avoid a serious energy crisis in coming decades. Among all the strategies reported, hydrogen energy is one of the most promising alternative energies. Several advantages, such as a high heat value [13], elemental abundance, and nontoxicity, have brought substantial attention to this carbon-free energy. Two solar-to-hydrogen pathways have been proposed and studied for decades, including photoelectrochemical (PEC) [14] and photocatalytic water splitting [15]. In these systems, specific semiconductor nanostructures are selected as photoelectrodes and photocatalysts and brought into contact with water molecules under solar light irradiation, dissociating water into hydrogen and oxygen. This system is cost-effective and simple for both laboratory and industrial production scales. In addition to hydrogen production, the reduction of carbon dioxide into solar fuels in PEC [16] and photocatalytic [17] processes has also triggered an everincreasing interest. This approach focuses on converting greenhouse gases into valuable chemicals, opening a new era of storing renewable energy in chemicals. Research on the conversion and storage of solar energy in terms of hydrogen or carbon-based fuels offers great potential for solving the sustainable energy challenge.

PEC systems are a viable platform for solar energy conversion. The PEC cell is inspired by the traditional electrochemical cell, in which solar energy and electrochemical 
bias collaborate to drive the desired redox reactions on the selected semiconductor photoelectrodes. With the help of an electrochemical bias, solar energy can be efficiently utilized, converted, and stored in another chemical form. Photocatalysts, in the form of particular nanostructures, are often used in a photocatalytic system in order to maximize the available catalytically active sites. Despite the low solar-to-fuel efficiency that is often reported [18-20], photocatalytic hydrogen production and carbon dioxide reduction are still feasible, and represent cost-effective solutions to meet the global energy demand. In general, single, plain semiconductors without further modifications suffer from pronounced charge carrier recombination due to Coulomb force. Upon photoexcitation, the negatively charged electrons in the conduction band are naturally bound to the positively charged holes in the valence band by the electrostatic Coulomb attraction [21]. For plain semiconductors, the bound electrons and holes are prone to recombination because of the lack of driving force of pulling them apart, limiting their further participation in surface redox reactions. The design and engineering of ingenious materials, such as heterostructure introduction [22], cocatalyst deposition [23] and dopant introduction [24-26], are thus essential to expediting the charge carrier transfer. If charge carriers survive recombination and live long enough, they can diffuse to the surface of the photoelectrodes and photocatalysts participating in the desired catalytic reactions. Whether the delocalized charge carriers can be effectively separated and injected into the electrolyte dramatically affects the overall PEC and photocatalytic performance. The charge transfer and recombination at the semiconductor surface is a relatively slow process that lies in the microseconds ( $\mu \mathrm{s})$ or even milliseconds (ms) timescale [27, 28]. Therefore, charge dynamics at the semiconductor's surface is the rate-determining step of the surface redox reactions and play a decisive role in the PEC and photocatalytic processes. A thorough analysis and study of the interfacial charge dynamics must be conducted beforehand in an effort to construct the true reaction mechanism for maximizing the solar-to-fuel conversion efficiency. In particular, for carbon dioxide reduction the entire reaction involves multielectron transfer pathways [29-31], which makes it exceedingly challenging to comprehend. Realizing the real reaction mechanism has thus become indispensable to the widespread deployment of PEC and photocatalytic techniques.

Transient absorption (TA) spectroscopy is a powerful tool for examining the charge transfer events of semiconductor nanostructures [32, 33]. Ex situ measurement is a common method for analyzing the charge dynamics properties of semiconductors by TA. During the measurements, the samples are either placed in air or dispersed in a specific solvent (water or ethanol) in order to meet the criteria of the spectroscopic setup. Although much progress has been made, the derived charge transfer scenarios from ex situ TA measurements are often distorted and unreliable because the operating conditions, such as external bias and electrolyte presence, are not considered. To address this issue, real-time investigation of charge dynamics via in situ TA experiments has drawn increasing attention. Important experimental factors, such as the application of electrochemical bias, the use of electrolytes and the concurrent occurrence of surface redox reactions, can be addressed by in situ measurements. In this Review, we summarize the recent progress of employing in situ TA spectroscopy when studying the interfacial charge dynamics of semiconductor nanostructures for hydrogen production and carbon dioxide reduction. As depicted in Scheme 1, representative research works that report the real-time charge dynamics of photoelectrodes and photocatalysts by conducting in situ TA measurements will be introduced. The content of this Review is divided into four parts. In the first part, we introduce the basic principle of employing TA spectroscopy when analyzing the charge dynamics of semiconductor nanostructures. Following that, previous studies on representative photoelectrodes $\left(\mathrm{TiO}_{2}, \mathrm{BiVO}_{4}, \mathrm{WO}_{3}, \alpha-\mathrm{Fe}_{2} \mathrm{O}_{3}\right)$ and photocatalysts $\left(\mathrm{Cu}_{2} \mathrm{O}, \mathrm{TiO}_{2}\right)$ are reviewed. Perspectives on the future directions for real-time charge dynamics of photoelectrodes and photocatalysts are provided at the end of the Review.

\section{TA spectroscopy}

TA spectroscopy is a typical pump-probe spectroscopic technique, which measures the temporal absorption changes of the samples before and after excitation [34]. A basic setup of TA spectroscopy is composed of an ultrafast monochromatic laser excitation, a low-energy broadband probing light and a spectrometer recording the absorbance of the samples [35]. The samples are first excited by an ultrafast fs pump laser. The duration of laser pulse should be carefully tuned to produce a suitable spectral width for studying specific excited state dynamics. After a certain amount of time, the absorbance of the samples is measured by a second probe beam. This probe beam usually ranges from 400 to $1000 \mathrm{~nm}$ and should be weak enough to avoid any multiphoton processes. By introducing a time variable, the absorbance variation profile over time can be collected and analyzed. As illustrated in Figure 1, the difference in the absorption spectrum $(\triangle A)$ is obtained by subtracting the absorption spectrum of the samples at the ground state $\left(A_{\text {pump }}\right.$, Figure $\left.1 \mathrm{~A}\right)$ from the absorption spectrum collected at the excited state 


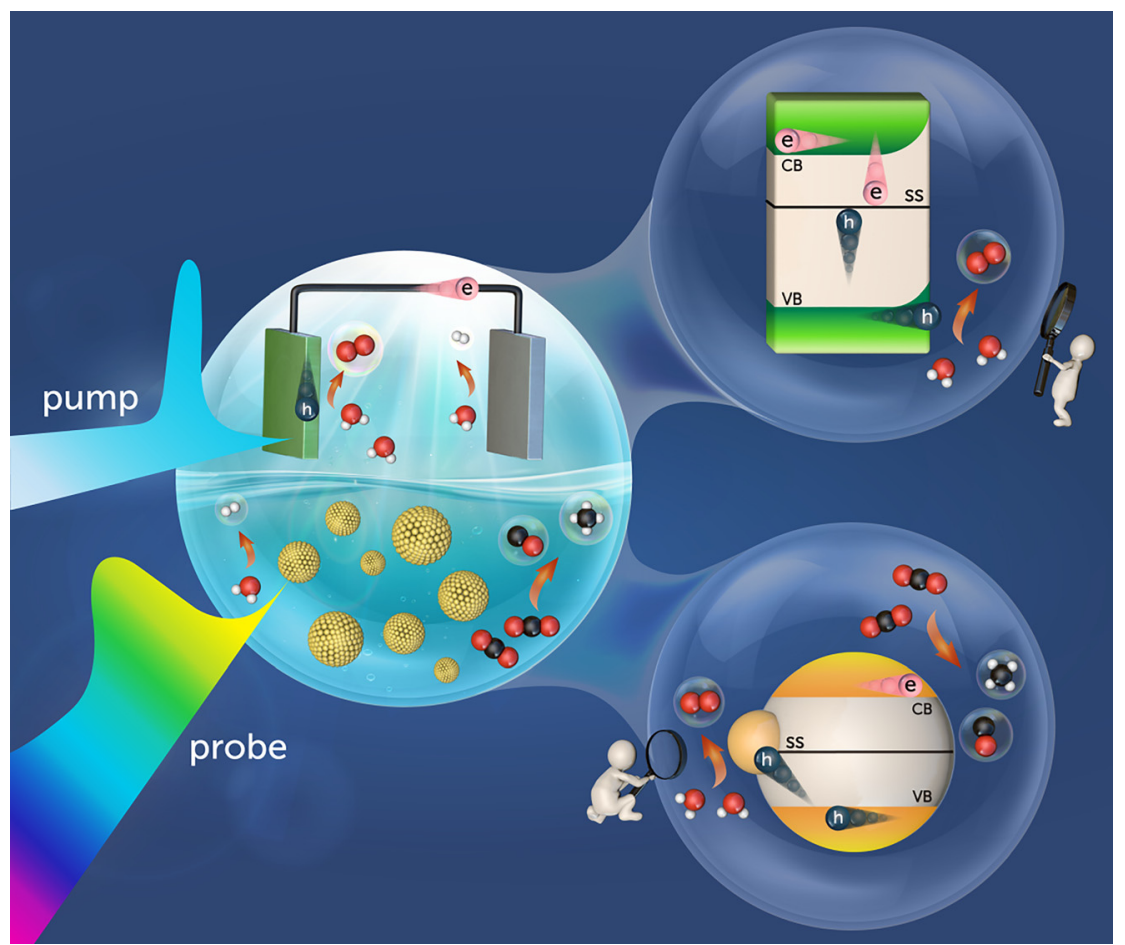

Scheme 1: Illustrations of employing in situ transient absorption (TA) spectroscopy to elucidate the veritable charge dynamics scenarios for semiconductor photoelectrodes and photocatalysts.
( $A_{\text {probe }}$, Figure 1B), i.e. $\Delta A=A_{\text {probe }}-A_{\text {pump }}$. The spectrum of $\Delta A$ as a function of delay time $(\tau)$ and wavelength $(\lambda)$ can be collected by tuning the delay time between the pump laser and probe beam (Figure 1C). Two types of spectroscopic profiles can be derived from the three-dimensional contour data, including a single-wavelength and a singletime point analysis. The single-wavelength profile can be interpreted to describe the excited states' deactivation processes, such as electron-hole recombination, interfacial charge transfer, charge trapping, etc. First-order trap state-mediated recombination and second-order free carrier recombination kinetics models can be used to analyze these kinetics processes both systematically and quantitatively. On the other hand, the single-time profile provides quantitative information of excited states' deactivation in a selected timeframe. Direct comparison of the variance of carrier concentration in a specific pathway is possible by simply evaluating the amplitude contribution of the TA component. There are four probable mechanisms accountable for different $\Delta A$ behaviors, which include ground state bleaching (GSB), stimulated emission (SE), excited state absorption (ESA) and product absorption (PA) [35, 36]. As displayed in Figure 1D, GSB originates from the reduced number of charge carriers in the ground state for the excited samples. In other words, the absorbance of the excited samples $\left(A_{\text {probe }}\right)$ is lower than the absorbance of the nonexcited samples ( $\left.A_{\text {pump }}\right)$, producing negative signals in the $\Delta A$ spectrum. SE refers to a two-level process, in which the photons of the probing light interact with the excited electrons, inducing an emission of additional photons with the spectral feature following the fluorescence of the samples. This transition causes an increase in transmitted intensity recorded by the detector, giving an intrinsically negative absorbance $\left(A_{\text {probe }}<0\right)$. Because SE only occurs in the excited state, the corresponding ground state absorption is supposed to be approaching zero $\left(A_{\text {pump }}=0\right)$, leading to negative $\Delta A$ signals in the TA profile. ESA on the other hand describes the charge carrier relaxation from the excited state to the higher excited state upon photoexcitation. Since only probing light is absorbed $\left(A_{\text {probe }}>0\right.$ and $A_{\text {pump }}=0$ ), positive $\Delta A$ signals are expected in the TA profile. Similar to ESA, PA represents specific electronic transition processes that only take place upon photoexcitation. Long-lived charge transfer events associated with triplet states, charge separation and isomeric transition are possible causes. Absorption of these events by probing light then appears as positive $\Delta A$ in the TA profile. TA spectroscopy allows us to monitor the charge carrier dynamics within semiconductor nanostructures by means of spectroscopic characterization. A thorough understanding of the photophysics beyond the collected TA data is essential for interpreting the interfacial charge dynamics of semiconductor nanostructures. 


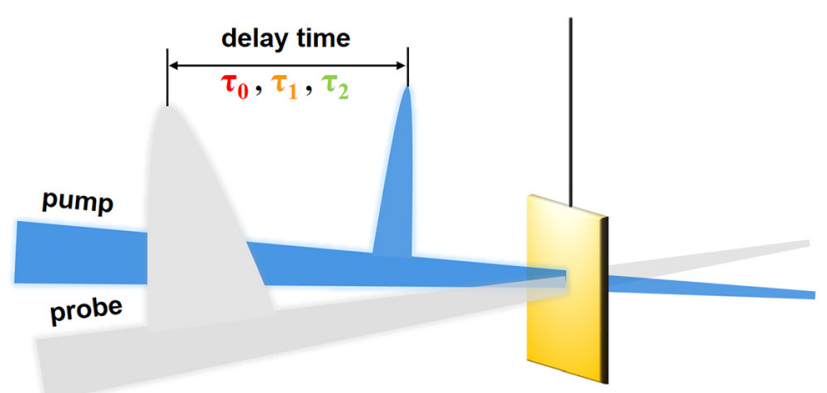

A
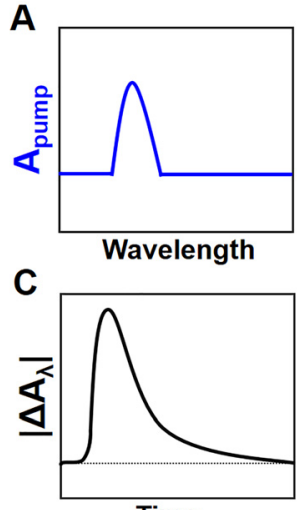

Time

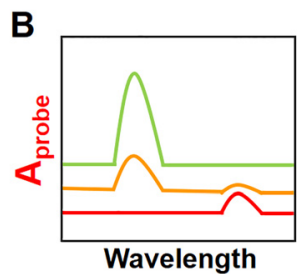

D

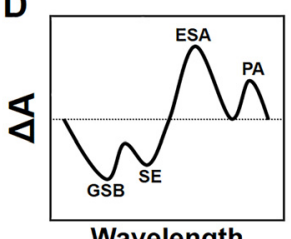

Wavelength

Figure 1: Basic mechanism of transient absorption (TA) spectroscopy.

(A) ground state absorption spectrum, (B) excited state absorption spectrum, (C) TA profile probed at a specific wavelength, (D) four possible mechanisms contributing to the recorded TA signals.

\section{PEC systems}

Charge carrier dynamics of semiconductor nanostructures in PEC systems have been studied and reported with the help of in situ TA spectroscopy. Several common semiconductor materials have been used as photoelectrodes when studying in situ TA, including $\mathrm{TiO}_{2}$ photoanodes [37-40], $\mathrm{BiVO}_{4}$ photoanodes [41, 42], $\mathrm{WO}_{3}$ photoanodes [43-45], $\alpha-\mathrm{Fe}_{2} \mathrm{O}_{3}$ photoanodes [46-50], and ZnTe photocathodes [51]. In this section, we introduce several representative works to highlight the importance of using in situ TA spectroscopy toward the realization of interfacial charge dynamics for photoelectrodes under operating conditions.

\section{1 $\mathrm{TiO}_{2}$ photoanodes}

Since the first report of the photoactivity property of $\mathrm{TiO}_{2}$ by Fujishima and Honda [52], this photoelectrode archetype has been thoroughly studied over the past few decades. $\mathrm{TiO}_{2}$ photoelectrodes have several advantages, such as having a high stability, a low cost, and being

environmental-friendly. Therefore, $\mathrm{TiO}_{2}$ has been widely used in various PEC applications, including PEC water splitting [53-58], PEC fuel cells [59], PEC dye degradation [60-62] and PEC sensing [63-66]. Cowan et al. reported the charge carrier dynamics within a $\mathrm{TiO}_{2}$ photoanode under PEC operating conditions [38]. Nanocrystalline rutile $\mathrm{TiO}_{2}$ films $\left(\mathrm{nc}-\mathrm{TiO}_{2}\right.$ ) were deposited on the conductive fluorine-doped tin oxide substrate. A linear-sweep voltammetry measurement revealed that the onset potential of anodic photocurrent was approximately $-0.8 \mathrm{~V}$ (vs. $\mathrm{Ag} / \mathrm{AgCl}$ ). The photocurrent reached a saturated value of $50 \mu \mathrm{A}$ at $-0.5 \mathrm{~V}$. In situ TA spectroscopy was used to quantitatively analyze the carrier dynamics, providing a better understanding of charge transfer scenarios during the PEC reaction. In Figure 2A, the TA data were collected at $10 \mu \mathrm{s}$ and $5 \mathrm{~ms}$ after the excitation of a $355 \mathrm{~nm}$ UV light (pump) at -0.9 and $0 \mathrm{~V}$. At $-0.9 \mathrm{~V}$ (a potential less anodic than the onset potential), a broad featureless absorption decay within a $10 \mu \mathrm{s}$ to $5 \mathrm{~ms}$ timescale was observed. Under UV excitation, the absorption band of the photoholes and trapped photoelectrons were located at 450 $[67,68]$ and $770 \mathrm{~nm}[69]$, respectively. Therefore, the overlapped absorption of the photoholes and trapped photoelectrons led to the broad featureless absorption decay. However, at a largely anodic bias $(0 \mathrm{~V})$, a strong absorption band around $460 \mathrm{~nm}$ was found, which could be attributed to the long-lived photoholes. A similar spectral feature attributable to the photoholes was also observed on platinized $\mathrm{nc}-\mathrm{TiO}_{2}\left(\mathrm{Pt}-\mathrm{nc}-\mathrm{TiO}_{2}\right)$ [70]. This absorption can still be observed at $5 \mathrm{~ms}$ after the UV excitation. In contrast, the absorption of trapped photoelectrons around $800 \mathrm{~nm}$ completely decayed within $5 \mathrm{~ms}$ after UV excitation. In Figure 2B, the decay profile was probed at $460 \mathrm{~nm}$ at $0 \mathrm{~V}$. This decay profile can be fitted by two decay components: (1) power law decay and (2) stretched exponential decay. The fast component (1) can be attributed to electron-hole recombination, while the slow component (2) can be assigned to the oxidation reaction between photoholes and water at the photoelectrode surface. The slow component has a lifetime of $30 \mathrm{~ms}$, suggesting that the formation of long-lived photoholes is a prerequisite for the water splitting reaction [71]. From the inset of Figure 2B, the TA profile of the photoholes showed a longer lifetime than the profile of the trapped photoelectrons. Meanwhile, the profile of the trapped photoelectrons was highly similar to the fast decay component of the TA profile of photoholes. Therefore, it can be concluded that the early stage of photoholes absorption is dominated by electron-hole recombination, and the oxidation reaction between photoholes and water contributes to the late stage of the decay profile. 


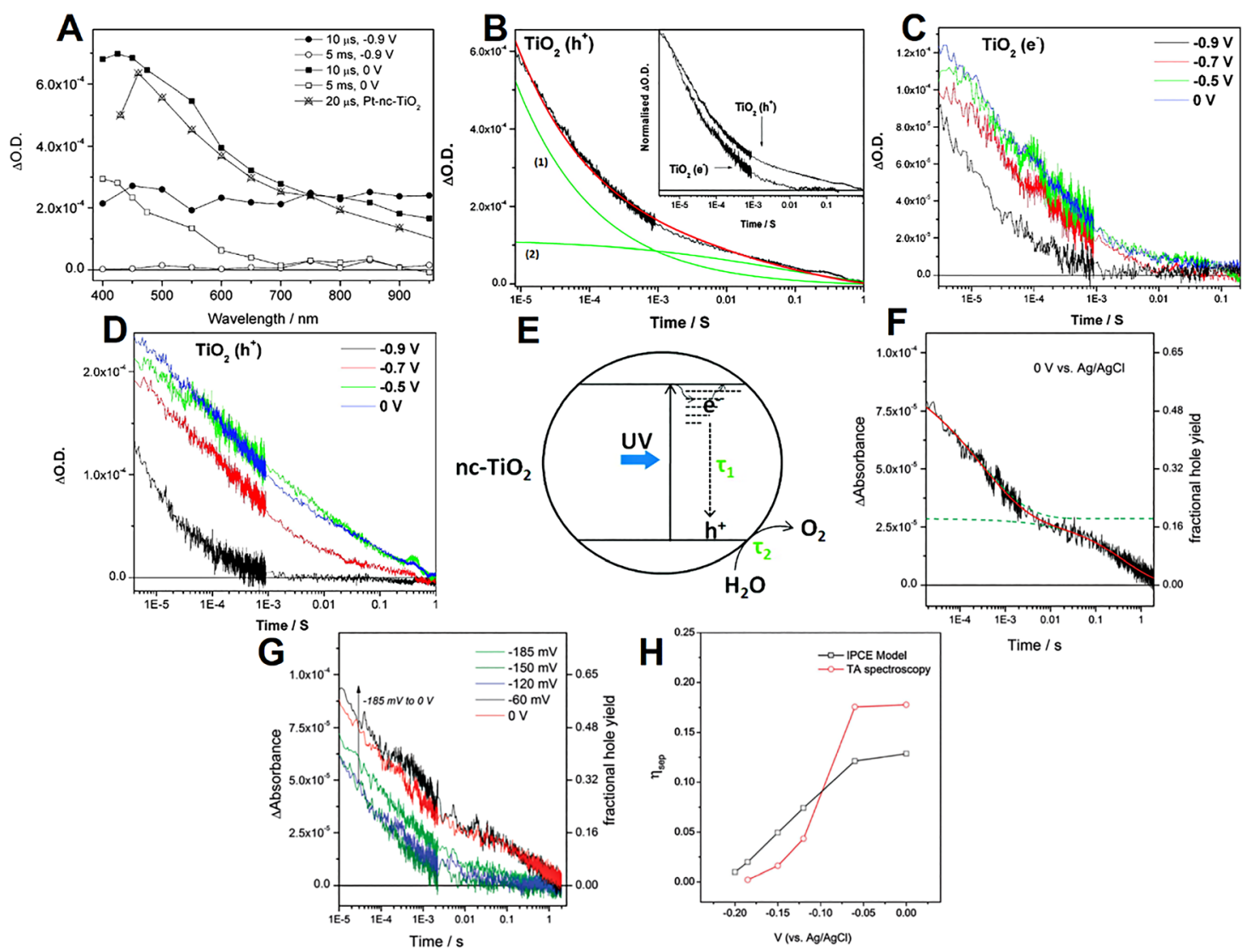

Figure 2: (A) In situ transient absorption (TA) spectra of $\mathrm{nc}^{-\mathrm{TiO}_{2}}$ recorded at -0.9 and $0 \mathrm{~V}$ in $0.05 \mathrm{M} \mathrm{NaOH}$ at $10 \mu \mathrm{s}$ and $5 \mathrm{~ms}$ after $\mathrm{UV}$ excitation $\left(355 \mathrm{~nm}, 250 \mu \mathrm{J} \mathrm{cm}^{-2}\right)$. The Pt-nc-TiO 2 spectrum was adopted from the literature [70]. (B) TA profile of the photoholes (460 nm) at $0 \mathrm{~V}$. Inset highlights the difference in the TA profile between the photoholes $(460 \mathrm{~nm})$ and trapped photoelectrons $(800 \mathrm{~nm})$. (C-D) TA profiles of trapped photoelectrons (C panel) and photoholes (D panel) under different applied biases. (E) Proposed charge dynamics mechanism of nc- $\mathrm{TiO}_{2}$. Reprinted with permission from a study by Cowan et al. [38]. Copyright 2010 American Chemical Society. (F) TA profile of photoholes for nc-TiO 2 $(460 \mathrm{~nm})$ at $0 \mathrm{~V}$ in $0.5 \mathrm{M} \mathrm{NaClO}_{4}$ under UV excitation $\left(355 \mathrm{~nm}, 35 \mu \mathrm{J} \mathrm{cm}^{-2}\right)$ and its correlation with the fractional yield of photoholes. (G) TA profiles of photoholes under different applied biases. $(\mathrm{H})$ Correlation of the two $\eta_{\text {sep }}$ values derived from incident photon-to-current conversion efficiency (IPCE) and TA measurements with the applied bias under UV excitation ( $355 \mathrm{~nm}$ and $3.7 \mathrm{~mW} \mathrm{~cm}^{-2}$ for IPCE; $355 \mathrm{~nm}$ and $35 \mu$ J cm ${ }^{-2}$ for TA). Reprinted with permission from a study by Cowan et al. [40]. Copyright 2013 Royal Society of Chemistry.

In Figure $2 \mathrm{C}$, the absorption of trapped photoelectrons gradually increased when the applied bias was anodically shifted from -0.9 to $0 \mathrm{~V}$. The electron density in the interband trap states decreased under a more anodic bias condition, and this decrease contributed to the prolonged lifetime of the trapped photoelectrons. The decay profiles of photoholes were also recorded under different applied biases. As shown in Figure 2D, these profiles again displayed two decay components. At a potential more anodic than $-0.5 \mathrm{~V}$, no appreciable change in the TA profile of photoholes could be found. This feature was consistent with the observed photocurrent saturation at $-0.5 \mathrm{~V}$. Noticeably, the electron-hole recombination (fast component) showed a decreased rate at a more anodic bias. This would result in a larger proportion of photoholes that could react with water, therefore enhancing the overall water oxidation efficiency. Figure 2E depicts the plausible charge dynamics pathways for an $\mathrm{nc}^{-\mathrm{TiO}_{2}}$ photoanode. After UV excitation, the photoholes would either recombine with the trapped photoelectrons or live long enough to react with water. Under an anodic bias condition, the trapped photoelectrons would be detrapped and transfer to the counter electrode, preventing them from recombining with photoholes. Meanwhile, the remaining photoholes would further react with the water, undergoing a water oxidation reaction.

Another study conducted by Cowan et al. researched the reasons for the low incident photon-to-current conversion efficiency (IPCE) of $\mathrm{nc}^{-\mathrm{TiO}_{2}}$ by analyzing the in situ TA data [40]. An equation commonly used to evaluate the factors affecting IPCE value can be shown by 
$\eta_{\text {IPCE }}(\lambda)=\eta_{\mathrm{LH}}(\lambda) \eta_{\text {sep }}(\lambda) \eta_{\text {col }}(\lambda)$. Here, light harvesting efficiency $\left(\eta_{\mathrm{LH}}\right)$ can be measured by UV-visible spectroscopy, which was 0.35 for an $\mathrm{nc}^{-\mathrm{TiO}_{2}}$ electrode with a thickness of $1.1 \mu \mathrm{m}$. The charge collection efficiency $\left(\eta_{\text {col }}(\lambda)\right)$ is approximated to be $\sim 1$ by considering that the electron diffusion length is larger than the photoanode thickness under a sufficiently large applied bias [72]. The charge separation efficiency $\left(\eta_{\text {sep }}(\lambda)\right)$ can then be derived from the equation. In Figure $2 \mathrm{~F}$, the TA profile of photoholes probed at $460 \mathrm{~nm}$ can be well fitted to a stretched biexponential function $\left(\Delta \mathrm{A}(t)=A_{1} e^{\left(-t / \tau_{1}\right)^{b_{1}}}+A_{2} e^{\left(-t / \tau_{2}\right)^{b_{2}}}\right)$. The absorption decay profiles of photoholes under various applied biases are further shown in Figure 2G. The fractional yield of photoholes, defined as $\left[h^{+}\right]_{t} /\left[h^{+}\right]_{t=0}$, was also computed from the slow decay component to represent the empirical value of $\eta_{\text {sep }}$. As the applied bias anodically shifted from -0.185 to $-0.060 \mathrm{~V}$ (vs. $\mathrm{Ag} / \mathrm{AgCl}$ ), the magnitude of the fast component increased due to a decrease in the electron-hole recombination rate. The suppression of the electron-hole recombination ensures the survival of long-lived photoholes, which are beneficial for water oxidation reactions. The magnitude of the slow component also increased as the photoanode was anodically biased from -0.185 to $-0.060 \mathrm{~V}$. At a bias more anodic than $-0.060 \mathrm{~V}$, no significant change in the TA signal was observed, which was again consistent with the photocurrent saturation recorded at $-0.060 \mathrm{~V}$. In Figure $2 \mathrm{H}$, the good agreement between the empirical $\eta_{\text {sep }}$ from TA profiles and the computed $\eta_{\text {sep }}$ from the IPCE measurements demonstrated the validity of both approaches for determining $\eta_{\text {sep }}$. In both experiments, $\eta_{\text {sep }}$ was found to increase with the applied bias from -0.185 to $-0.06 \mathrm{~V}$ prior to plateauing at a bias more anodic than $-0.06 \mathrm{~V}$. This result demonstrates that the charge separation efficiency is the main reason accounting for the photocurrent generation in a PEC water splitting reaction.

In order to enhance the PEC performance of $\mathrm{TiO}_{2}$, numerous strategies have been reported, such as foreigner element doping [55, 73], metal particle deposition [53, 56], type-II/Z-scheme heterojunction introduction [54, 57, 74], and photosensitizer incorporation [75, 76]. Pesci et al. studied oxygen-deficient, hydrogen-treated rutile $\mathrm{TiO}_{2}$ $\left(\mathrm{H}: \mathrm{TiO}_{2}\right)$ nanowire photoanodes [39] and conducted in situ TA measurements under various biases to establish a plausible charge dynamics mechanism. Figure $3 \mathrm{~A}$ shows the band structure of air-annealed $\left(\mathrm{A}: \mathrm{TiO}_{2}\right)$ and $\mathrm{H}: \mathrm{TiO}_{2}$. After the hydrogen treatment, the concentration of oxygen vacancies $\left(\mathrm{V}_{\mathrm{O}}\right)$ increases. Note that the energetic states of $\mathrm{V}_{\mathrm{O}}$ lie within the bandgap, which are around 0.75 and $1.18 \mathrm{~V}$ below the conduction band edge. These $\mathrm{V}_{\mathrm{O}}$ states can serve as electron donors (EDs) to increase the carrier concentration. In the PEC system under an applied bias, the increased donor concentration can also assist in suppressing electron-hole recombination because the photovoltage drop across the depletion layer is greatly enhanced. In Figure 3B, the linear-sweep voltammograms are in a good agreement with the TA amplitude change probed at $500 \mathrm{~nm}$ and $10 \mathrm{~ms}$ after excitation under various biases. Since photoholes play a decisive role in the water oxidation activity, the results of Figure 3B further validate that the TA signals in the $425-550 \mathrm{~nm}$ region were contributed to by the photohole dynamics of rutile $\mathrm{TiO}_{2}$. Figure 3C compares the in situ TA profiles between $\mathrm{H}: \mathrm{TiO}_{2}$ and $\mathrm{A}: \mathrm{TiO}_{2}$. At $-0.85 \mathrm{~V}$ (vs. $\mathrm{Ag} / \mathrm{AgCl}$ ), both $\mathrm{H}: \mathrm{TiO}_{2}$ and $\mathrm{A}: \mathrm{TiO}_{2}$ showed power law decay kinetics with a short carrier lifetime and indistinguishable kinetics profiles for the photoholes $(500 \mathrm{~nm})$ and trapped photoelectrons $(800 \mathrm{~nm})$ at the ms-sec timescale. This feature is characteristic of the pronounced electron-hole recombination. As the applied bias shifts anodically to $-0.6 \mathrm{~V}$, there is a relatively large increase in the absorbance for $\mathrm{H}: \mathrm{TiO}_{2}$ at the early timescale (1-10 $\mu \mathrm{s})$. Such an absorbance increase reflects an increased yield of photoelectrons and photoholes, indicating the suppression of fast recombination under an anodic bias. In contrast, $\mathrm{A}: \mathrm{TiO}_{2}$ shows a minimal change in the charge carrier yield as the applied bias is anodically varied. This outcome suggests that the early charge separation process is essential to enhancing the photoactivity of $\mathrm{H}: \mathrm{TiO}_{2}$. Another conspicuous feature from Figure $3 \mathrm{C}$ is that the decay kinetics of photoelectrons and photoholes are decoupled at the ms-sec timescale. This observation indicates that processes other than electron-hole recombination can occur under anodic bias conditions. In Figure 3D, the TA profiles of photoholes $(500 \mathrm{~nm})$ and trapped photoelectrons $(800 \mathrm{~nm})$ at $-0.6 \mathrm{~V}$ for $\mathrm{H}^{\mathrm{TiO}}{ }_{2}$ and A: $\mathrm{TiO}_{2}$ are compared. For $\mathrm{H}: \mathrm{TiO}_{2}$, the trapped photoelectrons decay by more than $50 \%$ in the early stage $(10 \mu$ s to $1 \mathrm{~ms}$ ), whereas the photoholes remain almost unchanged at the same timescale. The fast decay of trapped photoelectrons follows a power law kinetics model $(\tau=14 \mathrm{~ms})$ and is attributed to the electron transfer to the external circuit. However, the slow decay of photoholes can be well fitted with a single stretched exponential function $(\tau=0.15 \mathrm{~s})$ and is assigned to the hole injection into the electrolyte. This timescale is at the same magnitude with the photohole lifetime ( $\tau=0.03-0.4 \mathrm{~s}$ ) required for effective water oxidation on anatase $\mathrm{TiO}_{2}$ photoelectrodes [77]. Conversely, on $\mathrm{A}: \mathrm{TiO}_{2}$, the photohole decay profile at $-0.6 \mathrm{~V}$ can be fitted by a combination of stretched exponential and power law functions, implying there are at least two probable photohole transfer pathways. The fast 
A

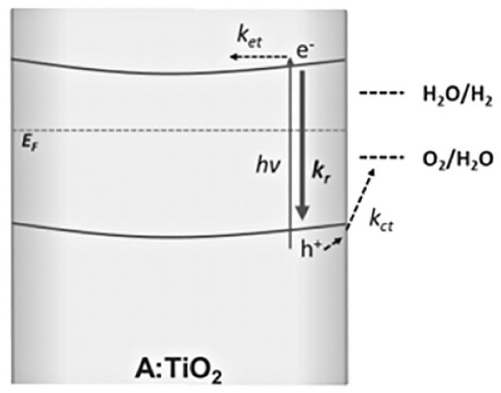

$\mathrm{A}: \mathrm{TiO}_{2}$

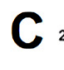

C 2
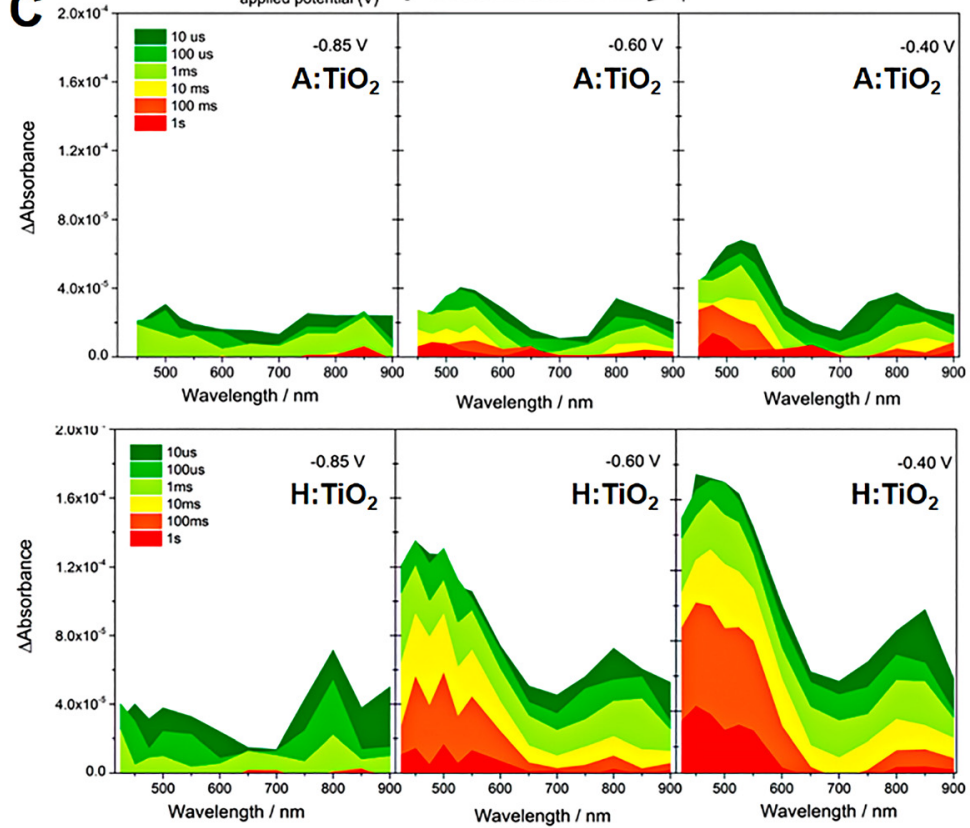
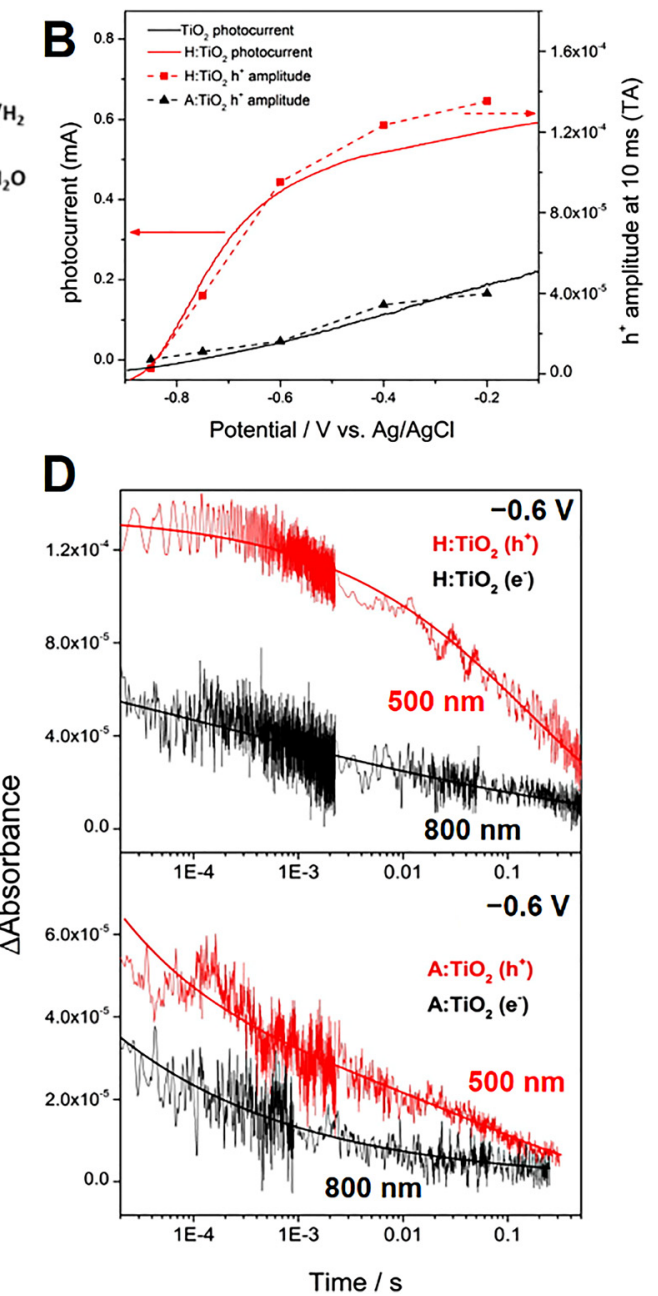

Figure 3: (A) Proposed charge dynamics mechanism of A: $\mathrm{TiO}_{2}$ and $\mathrm{H}: \mathrm{TiO}_{2}$ at an anodic bias after UV excitation. $k_{\mathrm{ct}}, k_{\mathrm{r}}$ and $k_{\mathrm{et}}$ respectively stand for the rate constants of the charge transfer into the solution, the charge recombination, and the electron transfer. $E_{10}$ and $E_{20}$ respectively denote the two states of $\mathrm{V}_{O}$ at 0.75 and $1.2 \mathrm{eV}$ below the conduction band edge. (B) Linear-sweep voltammograms and in situ transient absorption (TA) amplitude change at $500 \mathrm{~nm}$ and $10 \mathrm{~ms}$ after UV excitation $\left(\lambda=355 \mathrm{~nm}, 70 \mu \mathrm{J} \mathrm{cm}^{-2}\right)$ for A:TiO $\mathrm{T}_{2}$ and $\mathrm{H}: \mathrm{TiO}_{2}$ in $1 \mathrm{M} \mathrm{NaOH}$ under various applied biases. (C) TA profiles of $\mathrm{A}: \mathrm{TiO}_{2}$ and $\mathrm{H}: \mathrm{TiO}_{2}$ at different applied biases. (D) TA decay profiles of photoholes (500 nm) and trapped photoelectrons $(800 \mathrm{~nm})$ for $\mathrm{H}: \mathrm{TiO}_{2}$ and $\mathrm{A}: \mathrm{TiO}_{2}$ at $-0.6 \mathrm{~V}$. Reprinted with permission from a study by Pesci et al. [39]. Copyright 2013 American Chemical Society.

decay component is assigned to electron-hole recombination, whereas the slow decay component is attributed to a photohole injection into the solution. These two events compete with one another and deteriorate the water oxidation activity.

\section{2 $\mathrm{BiVO}_{4}$ photoanodes}

$\mathrm{BiVO}_{4}$ is an n-type semiconductor with a narrow bandgap $\left(E_{\mathrm{g}}=2.4 \mathrm{eV}\right)$ that is suitable for visible light absorption. In addition, the relatively cathodic valence band edge $\left(E_{\mathrm{VB}}=+2.5 \mathrm{~V}\right.$ vs. NHE) [78] is able to drive many oxidation reactions. However, $\mathrm{BiVO}_{4}$ suffers from a short hole diffusion length that makes the overall solar-to-fuel efficiency low. Zhang et al. reported a black phosphorene (BP)-deposited $\mathrm{BiVO}_{4}\left(\mathrm{BP} / \mathrm{BiVO}_{4}\right)$ nanostructure photoanode, in which the BP layer could facilitate photohole extraction as a result of the $p-n$ band alignment, promoting the overall water oxidation efficiency. The morphology of the prepared $\mathrm{BiVO}_{4}$ and $\mathrm{BP} / \mathrm{BiVO}_{4}$ nanostructures is revealed in Figure 4A, showing a thickness of approximately $1 \mu \mathrm{m}$. In order to elucidate the veritable charge dynamics of BP/BVO, in situ TA measurements were performed. Note that the TA signals of the photoholes of BP/BVO are situated around 400-700 $\mathrm{nm}$ [79]. To acquire information on the photohole dynamics, the TA profiles were probed at $500 \mathrm{~nm}$ under open-circuit 

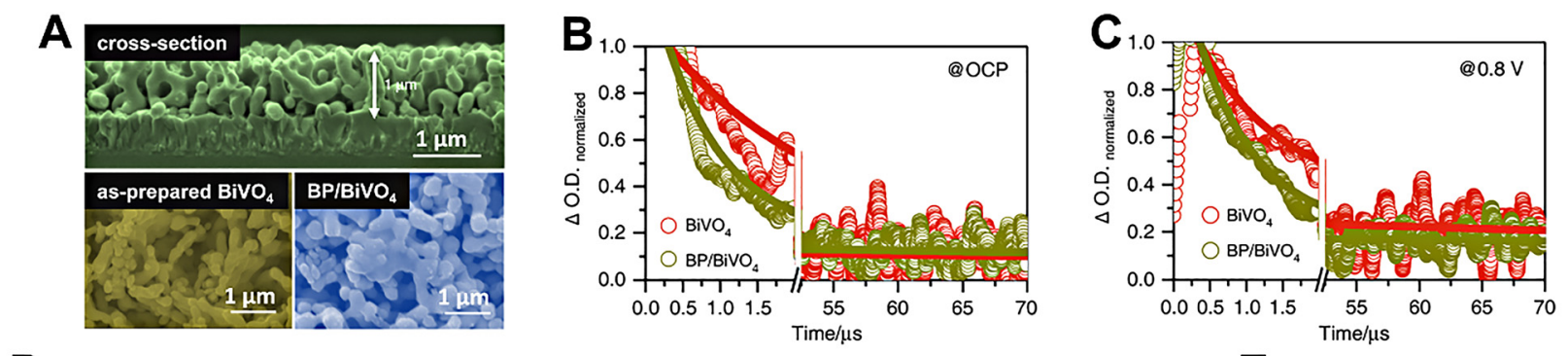

D

\begin{tabular}{c|c|c|c|c|c}
\hline Sample & $\mathrm{A}_{1}(\%)$ & $\tau_{1}(\mu \mathrm{s})$ & $\mathrm{A}_{2}(\%)$ & $\tau_{2}(\mu \mathrm{s})$ & Condition \\
\hline \multirow{2}{*}{$\mathrm{BiVO}_{4}$} & $85.5( \pm 1.5)$ & $2.169( \pm 0.005)$ & $14.5( \pm 0.3)$ & $141.97( \pm 9.62)$ & $\mathrm{OCP}$ \\
\cline { 2 - 6 } & $72.2( \pm 2.0)$ & $1.201( \pm 0.008)$ & $27.8( \pm 0.2)$ & $141.17( \pm 2.954)$ & $0.8 \mathrm{~V}$ \\
\hline \multirow{2}{*}{$\mathrm{BP} / \mathrm{BiVO}_{4}$} & $86.1( \pm 1.9)$ & $0.830( \pm 0.020)$ & $13.9( \pm 0.1)$ & $147.15( \pm 5.05)$ & OCP \\
\cline { 2 - 6 } & $85.6( \pm 2.0)$ & $0.820( \pm 0.019)$ & $14.4( \pm 0.1)$ & $280.25( \pm 11.35)$ & $0.8 \mathrm{~V}$ \\
\hline
\end{tabular}

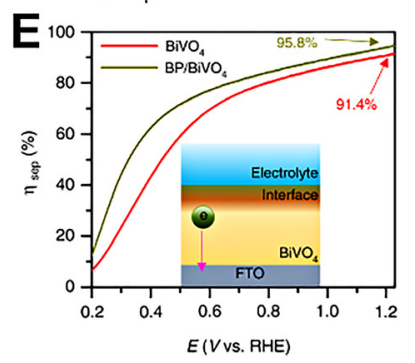

Figure 4: (A) SEM images of $\mathrm{BiVO}_{4}$ and black phosphorene (BP)/BiVO ${ }_{4}$ ( $\left.\mathrm{B}-\mathrm{C}\right)$ In situ TA profiles of the photoholes $(500 \mathrm{~nm})$ for $\mathrm{BiVO}{ }_{4}$ and $\mathrm{BP} /$ $\mathrm{BiVO}_{4}$ at OCP (B panel) and $0.8 \mathrm{~V}$ (C panel) in $0.5 \mathrm{M} \mathrm{KPi}$. (D) Fitting parameters of the recorded TA profiles. (E) $\eta_{\text {sep }}$ of $\mathrm{BiVO}_{4}$ and $\mathrm{BP} / \mathrm{BiVO}{ }_{4}$ at different applied biases. Reprinted with permission from a study by Zhang et al. [42]. Copyright 2019 Springer Nature.

potential (OCP) and $0.8 \mathrm{~V}$ (vs. $\mathrm{Ag} / \mathrm{AgCl})$. In Figure $4 \mathrm{~B}$ and $\mathrm{C}$, the collected TA spectra are fitted by a biexponential decay model $\left(\Delta \mathrm{A}(t)=A_{1} e^{\left(-t / \tau_{1}\right)}+A_{2} e^{\left(-t / \tau_{2}\right)}\right)$ composed of a fast decay component $\left(\tau_{1}\right)$ and a slow decay $\left(\tau_{2}\right)$. The corresponding fitting parameters are summarized in Figure 4D. The fast component $\left(\tau_{1}\right)$ can be ascribed to the trapping of photoholes at the band edge of $\mathrm{BiVO}_{4}$, and the slow component $\left(\tau_{2}\right)$ can be attributed to photohole trapping at the electrode/electrolyte interface. Under an applied bias of $0.8 \mathrm{~V}$, both pure $\mathrm{BiVO}_{4}$ and $\mathrm{BP} / \mathrm{BiVO}_{4}$ displayed a reduced $\tau_{1}$, which can be understood by the fact that an applied bias can facilitate photohole transportation. The $\tau_{2}$ value of pure $\mathrm{BiVO}_{4}$ remained unchanged at $0.8 \mathrm{~V}$, while the $\tau_{2}$ value of $\mathrm{BP} / \mathrm{BiVO}_{4}$ doubled. The twofold increase of $\tau_{2}$ indicated that the photoholes were efficiently extracted from $\mathrm{BiVO}_{4}$ to the electrode/ electrolyte interface by BP deposition. The increased yield of the photoholes was expected to promote the water oxidation performance. The charge separation efficiencies $\left(\eta_{\text {sep }}\right)$ were also measured and shown in Figure 4E, which showed a $4.4 \%$ enhancement via BP deposition under $1.23 \mathrm{~V}$ (vs. RHE). This result further corroborates the beneficial function of $\mathrm{BP}$ as a photohole extractor.

Another strategy for enhancing the solar-to-fuel efficiency of $\mathrm{BiVO}_{4}$ is to introduce a type-II band alignment, which can achieve a pronounced charge carrier separation. $\mathrm{WO}_{3}$-modified $\mathrm{BiVO}_{4}\left(\mathrm{WO} / \mathrm{BiVO}_{4}\right)$ is a common type-II heterostructure model studied in PEC water splitting systems. The band alignment allows photoelectrons to flow from the $\mathrm{BiVO}_{4}$ to the $\mathrm{WO}_{3}$ domain, leaving the photoholes in the $\mathrm{BiVO}_{4}$ domain to conduct a water oxidation reaction. Selim et al. [80] reported the interfacial charge dynamics of $\mathrm{WO}_{3} / \mathrm{BiVO}_{4}$ by using in situ TA spectroscopy. Figure $5 \mathrm{~A}$ and $\mathrm{B}$ shows the TA spectra under $1.23 \mathrm{~V}$ (vs. RHE) and OCP at $10 \mu$ s and $10 \mathrm{~ms}$ after excitation. Note that the samples were excited from the $\mathrm{BiVO}_{4}$ side with the aim of exclusively studying the dynamics of the charge transfer from $\mathrm{BiVO}_{4}$ to $\mathrm{WO}_{3}$. Under $1.23 \mathrm{~V}$, the TA profile of pure $\mathrm{BiVO}_{4}$ exhibits a maximum absorption at $550 \mathrm{~nm}$, whereas the TA profile of $\mathrm{WO}_{3} / \mathrm{BiVO}_{4}$ shows an additional absorption band at a long wavelength that disappears by $10 \mathrm{~ms}$. Previous work has shown that the photoelectrons of $\mathrm{WO}_{3}$ exhibit a broad absorption around $800 \mathrm{~nm}[45,81]$. Because $\mathrm{WO}_{3}$ was not excited in the current TA setup, the photoelectron signal of $\mathrm{WO}_{3}$ at a long wavelength region was attributed to the photoelectron transfer from $\mathrm{BiVO}_{4}$ to $\mathrm{WO}_{3}$ at a $\mu$ s timescale. However, at the OCP there was no noticeable difference in the $\mathrm{TA}$ decay between $\mathrm{BiVO}_{4}$ and $\mathrm{WO}_{3} / \mathrm{BiVO}_{4}$. Importantly, the lack of a photoelectron signal for $\mathrm{WO}_{3} / \mathrm{BiVO}_{4}$ suggested that an applied bias was necessary for prompting the photoelectron transfer from $\mathrm{BiVO}_{4}$ to $\mathrm{WO}_{3}$. In Figure $5 \mathrm{C}$ and $\mathrm{D}$, the TA profiles of photoholes $(500 \mathrm{~nm})$ of pure $\mathrm{BiVO}_{4}$ and $\mathrm{WO}_{3} / \mathrm{BiVO}_{4}$ were compared under different applied biases. These kinetics traces could be fitted with a combination of a power law and a single exponential function. The photohole yield increased with 
an increasing anodic bias, with $\mathrm{WO}_{3} / \mathrm{BiVO}_{4}$ showing a more pronounced enhancement. Note than the anodic bias could create a wider depletion layer at the electrode/ electrolyte interface, which increased the band bending to promote photohole accumulation at the photoanode surface. For pure BiVO4, which showed biphasic TA kinetics, two pathways of photohole dynamics were considered: trap-mediated bimolecular recombination at an early timescale ( $\mu \mathrm{s}-\mathrm{ms})$ and water oxidation process coupled with back electron-hole recombination at a slow timescale (ms-sec). Compared with $\mathrm{BiVO}_{4}(\tau=0.18 \mathrm{~s}$ at $1.2 \mathrm{~V}), \mathrm{WO}_{3} / \mathrm{BiVO}_{4}$ showed an increased lifetime of photoholes $(\tau=0.29 \mathrm{~s}$ at $1.2 \mathrm{~V}$ ), demonstrating the suppression of bimolecular recombination by the introduction of $\mathrm{WO}_{3}$. The plausible charge dynamics mechanism is shown in Figure $5 \mathrm{E}$ and $\mathrm{F}$. In pure $\mathrm{BiVO}_{4}$, photoholes suffer from bimolecular recombination, and thus the water oxidation performance is limited. With the introduction of $\mathrm{WO}_{3}$, photoelectron transfer from $\mathrm{BiVO}_{4}$ to $\mathrm{WO}_{3}$, prohibiting charge carriers from bimolecular recombination. This results in the formation of long-lived photoholes at $\mathrm{BiVO}_{4}$, which has been considered as a requisite for driving efficient water oxidation on $\mathrm{BiVO}_{4}$ [82].

\section{3 $\mathrm{WO}_{3}$ photoanodes}

$\mathrm{WO}_{3}$ is another well-reported n-type semiconductor for use as a photoanode in PEC water splitting thanks to the visible light-responsive band structure $\left(E_{\mathrm{g}}=2.5 \mathrm{eV}\right)$. However, the fast charge recombination at the surface defect sites ( $\mathrm{W}^{5+}$ and surface states) hinders the overall PEC performance. Several strategies have been proposed to address this issue, such as hydrogen treatment [83, 84], co-catalyst deposition [85-87] and passivation layer introduction [88, 89]. Kim et al. reported an efficient surface passivation approach for decreasing the photoelectron trapping event for $\mathrm{WO}_{3}$ using an $\mathrm{Al}_{2} \mathrm{O}_{3}$ overlayer [44]. The photoanode was fabricated by depositing a 5.3-nm-thick $\mathrm{Al}_{2} \mathrm{O}_{3}$ layer on $\mathrm{WO}_{3}$ thin films $\left(\mathrm{WO}_{3} / \mathrm{Al}_{2} \mathrm{O}_{3}\right)$. The deposited $\mathrm{Al}_{2} \mathrm{O}_{3}$ not only promoted photoelectron transfer to the external circuit by passivating the electron traps but also boosted the water oxidation kinetics by arousing the photohole trapping process. The photoelectron trapping event was first examined with a steadystate absorption spectroscopy under two distinct applied biases, one above the photocurrent onset (1.3 V [vs. $\mathrm{Ag} / \mathrm{AgCl}])$ and the other one below the photocurrent onset
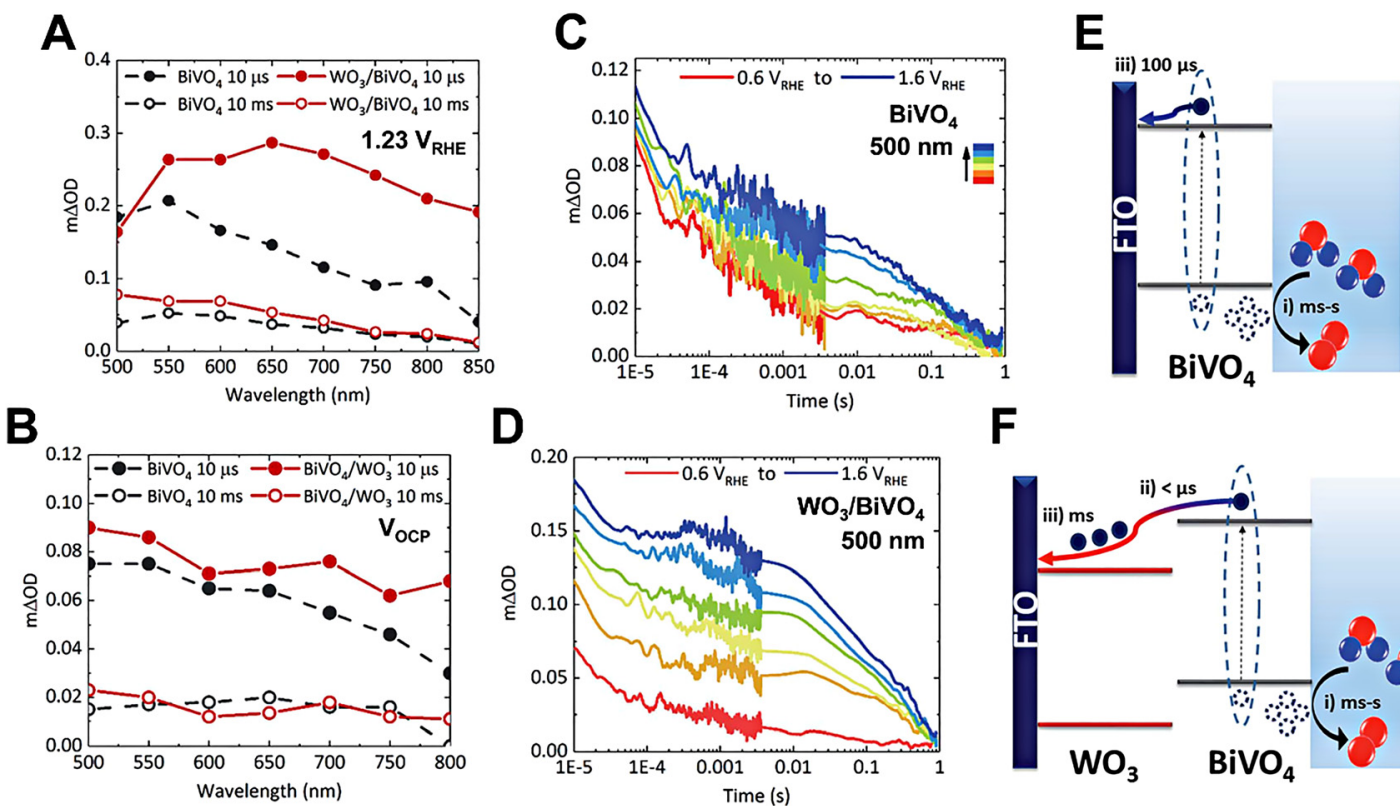

$\mathbf{F}$

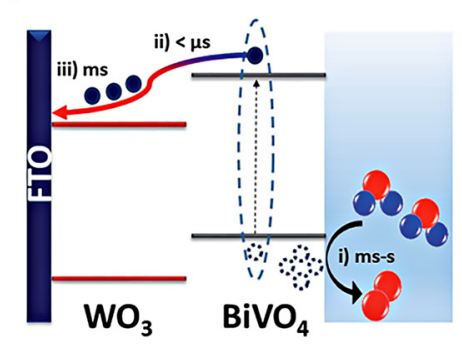

Figure 5: (A, B) In situ transient absorption ( $\mathrm{TA}$ ) spectra of $\mathrm{BiVO}_{4}$ and $\mathrm{WO}_{3} / \mathrm{BiVO}_{4}$ at $1.23 \mathrm{~V}$ (A panel) and open-circuit potential (OCP) (B panel) in a $0.1 \mathrm{M}$ phosphate buffer recorded at $10 \mu \mathrm{s}$ and $10 \mathrm{~ms}$ after UV excitation $\left(355 \mathrm{~nm}, 500 \mu \mathrm{cm}^{-2}\right)$. (C, D) TA profiles of photoholes (500 nm) of $\mathrm{BiVO}_{4}$ and $\mathrm{WO}_{3} / \mathrm{BiVO}_{4}$ at different applied biases. (E, F) Proposed charge dynamics mechanism of $\mathrm{BiVO}_{4}$ and $\mathrm{WO}_{3} / \mathrm{BiVO}_{4}$, in which (i) represents water oxidation at the $\mathrm{BiVO}_{4}$ surface, (ii) denotes the electron transfer from $\mathrm{BiVO}_{4}$ to $\mathrm{WO}_{3}$ and (iii) stands for the photoelectron extraction from the photoanode to the external circuit. Reprinted with permission from a study by Selim et al. [80] Copyright 2013 Royal Society of Chemistry. 

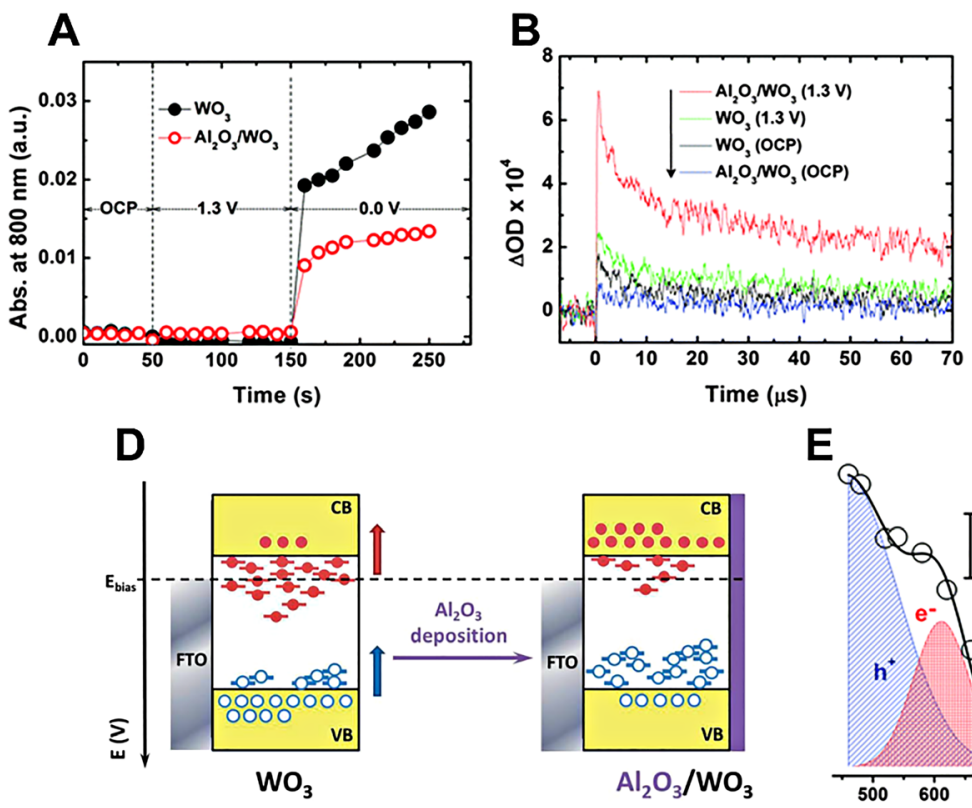
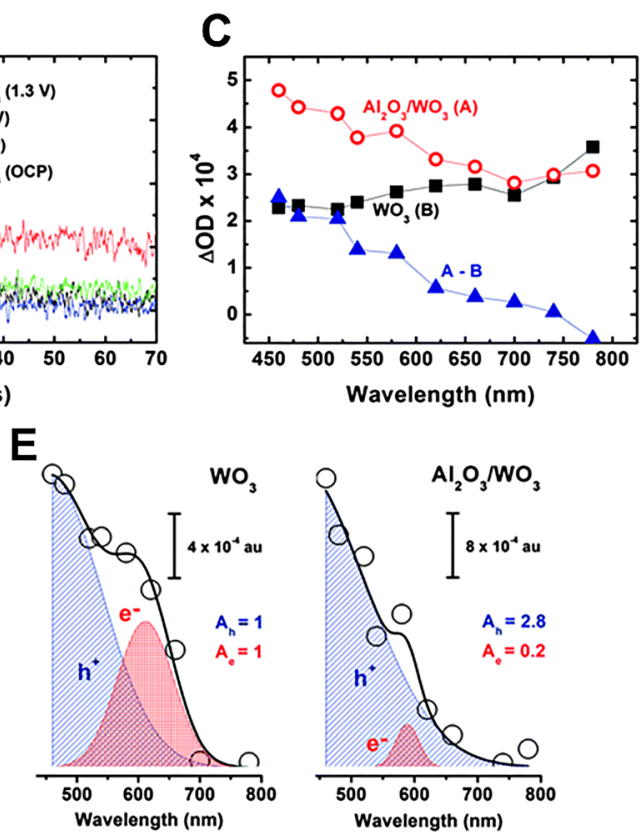

Figure 6: (A) Absorbance change at $800 \mathrm{~nm}$ for pure $\mathrm{WO}_{3}$ and $\mathrm{Al}_{2} \mathrm{O}_{3} / \mathrm{WO}_{3}$ at different applied biases in Ar-purged $0.1 \mathrm{M} \mathrm{HClO}$. (B) Transient absorption (TA) profiles of photoholes $(480 \mathrm{~nm})$ at open-circuit potential (OCP) and $1.3 \mathrm{~V}$ after UV excitation ( $355 \mathrm{~nm}, 250 \mu \mathrm{J}$ pulse ${ }^{-1}$ ). (C) TA spectra of pure $\mathrm{WO}_{3}$ and $\mathrm{Al}_{2} \mathrm{O}_{3} / \mathrm{WO}_{3}$ at $1.3 \mathrm{~V}$ and $2 \mu \mathrm{s}$ after UV excitation. $\mathrm{A}, \mathrm{B}$ represents the subtracted spectrum. (D) Proposed charge dynamics mechanism of pure $\mathrm{WO}_{3}$ and $\mathrm{Al}_{2} \mathrm{O}_{3} / \mathrm{WO}_{3}$ under a bias condition. (E) Deconvoluted $\mathrm{TA}_{\mathrm{spectra}}$ of pure WO $\mathrm{W}_{3}$ and $\mathrm{Al}_{2} \mathrm{O}_{3} / \mathrm{WO}_{3}$ at $1.3 \mathrm{~V}$ and $2 \mu \mathrm{s}$ after UV excitation. Reprinted with permission from a study by Kim et al. [44]. Copyright 2013 Royal Society of Chemistry.

(0 V [vs. $\mathrm{Ag} / \mathrm{AgCl}])$. In Figure 6A, the absorbance change at $800 \mathrm{~nm}$ of pure $\mathrm{WO}_{3}$ and $\mathrm{Al}_{2} \mathrm{O}_{3} / \mathrm{WO}_{3}$ was measured under a bias condition. Here, the absorption at $800 \mathrm{~nm}$ could be attributed to photoelectron trapping signal of $\mathrm{WO}_{3}$ [90], which remained unchanged at $1.3 \mathrm{~V}$, despite the deposition of $\mathrm{Al}_{2} \mathrm{O}_{3}$. However, at $0 \mathrm{~V}$ there was a notable absorbance increase indicative of photoelectron accumulation on both pure $\mathrm{WO}_{3}$ and $\mathrm{Al}_{2} \mathrm{O}_{3} / \mathrm{WO}_{3}$. Importantly, the photoelectron accumulation of $\mathrm{WO}_{3}$ (absorbance at $800 \mathrm{~nm}$ ) was largely reduced upon the deposition of $\mathrm{Al}_{2} \mathrm{O}_{3}$. This result indicates that $\mathrm{Al}_{2} \mathrm{O}_{3}$ could passivate the electron traps of $\mathrm{WO}_{3}$ to promote photoelectron transfer to the external circuit. This would further mediate the photohole dynamics of $\mathrm{WO}_{3}$ to affect the overall PEC performance.

In situ TA spectroscopy was further performed to investigate the photohole dynamics. In Figure 6B, the TA profiles of trapped photoholes (480 nm [81]) at OCP and $1.3 \mathrm{~V}$ for pure $\mathrm{WO}_{3}$ and $\mathrm{Al}_{2} \mathrm{O}_{3} / \mathrm{WO}_{3}$ were compared. The yield of the trapped photoholes (i.e., the TA intensity) of $\mathrm{Al}_{2} \mathrm{O}_{3} / \mathrm{WO}_{3}$ was largely increased at $1.3 \mathrm{~V}$, while the increased photohole yield of pure $\mathrm{WO}_{3}$ was less pronounced. This comparison suggests that $\mathrm{Al}_{2} \mathrm{O}_{3}$ passivation can enhance the number of trapped photoholes for $\mathrm{WO}_{3}$. To confirm this argument, the TA spectra of pure
$\mathrm{WO}_{3}$ at $1.3 \mathrm{~V}$ and $2 \mu \mathrm{s}$ after $\mathrm{UV}$ excitation were subtracted from those of $\mathrm{Al}_{2} \mathrm{O}_{3} / \mathrm{WO}_{3}$ to reveal the photohole population as a result of the $\mathrm{Al}_{2} \mathrm{O}_{3}$ passivation. As Figure $6 \mathrm{C}$ shows, the spectral subtraction (A, B) reveals a substantial increase in the photohole trapping signal at $480 \mathrm{~nm}$. This outcome corroborates that the increased photohole trapping also contributed to the better PEC performance of $\mathrm{Al}_{2} \mathrm{O}_{3} / \mathrm{WO}_{3}$. Figure $6 \mathrm{D}$ depicts the proposed charge dynamics mechanism for pure $\mathrm{WO}_{3}$ and $\mathrm{Al}_{2} \mathrm{O}_{3} / \mathrm{WO}_{3}$. For pure $\mathrm{WO}_{3}$, trapped photoelectrons dominated the charge transfer dynamics to hinder the PEC performance. Upon $\mathrm{Al}_{2} \mathrm{O}_{3}$ deposition, the electron traps of $\mathrm{WO}_{3}$ could be passivated, accompanied by an increased population of trapped photoholes, both of which were beneficial for PEC water oxidation. In Figure 6E, the deconvoluted TA spectra could be utilized to quantify the number of trapped photoelectrons and photoholes for pure $\mathrm{WO}_{3}$ and $\mathrm{Al}_{2} \mathrm{O}_{3} / \mathrm{WO}_{3}$. The trapped photohole population of $\mathrm{Al}_{2} \mathrm{O}_{3} / \mathrm{WO}_{3}$ was three times higher than that of pure $\mathrm{WO}_{3}$. On the other hand, the number of trapped photoelectrons of $\mathrm{Al}_{2} \mathrm{O}_{3} / \mathrm{WO}_{3}$ was merely $20 \%$ of the number of $\mathrm{Al}_{2} \mathrm{O}_{3} /$ $\mathrm{WO}_{3}$. This result confirmed the benefit of $\mathrm{Al}_{2} \mathrm{O}_{3}$ deposition for enhancing the PEC water oxidation activity of $\mathrm{WO}_{3}$ by mediating interfacial charge dynamics. 


\section{$3.4 \alpha-\mathrm{Fe}_{2} \mathrm{O}_{3}$ photoanodes}

$\alpha-\mathrm{Fe}_{2} \mathrm{O}_{3}$ (hematite) is a well-reported promising photoanode material with several advantages. The bandgap of $\alpha-\mathrm{Fe}_{2} \mathrm{O}_{3}\left(E_{\mathrm{g}}=2.1 \mathrm{eV}\right)$ [91] is capable of visible light absorption, and the valence band edge $\left(E_{\mathrm{VB}}=+2.38 \mathrm{~V}\right.$ vs. NHE) [92, 93] is thermodynamically suitable for water oxidation reactions. However, there are several intrinsic properties that deteriorate the solar-to-fuel efficiency of $\alpha-\mathrm{Fe}_{2} \mathrm{O}_{3}$. The drawbacks include limited photon harvesting due to the high light penetration depth [94], and the incapability of hydrogen production because of an unfavorable conduction band edge $\left(E_{\mathrm{CB}}=+0.28 \mathrm{~V}\right.$ vs. $\left.\mathrm{NHE}\right)$ [95], as well as sluggish water oxidation kinetics resulting from a short photohole diffusion [96]. The issue of photohole dynamics is particularly critical, thus invigorating broad interests in studying the charge dynamics of $\alpha-\mathrm{Fe}_{2} \mathrm{O}_{3}$. Barroso et al. [47] reported a perspective that summarized the recent studies on interfacial charge dynamics for $\alpha-\mathrm{Fe}_{2} \mathrm{O}_{3}$ by employing in situ TA spectroscopy. Figure 7A shows the in situ TA spectra at $800 \mathrm{~nm}$ for Si-doped $\alpha-\mathrm{Fe}_{2} \mathrm{O}_{3}$ photoanode. Under $0.5 \mathrm{~V}$ (vs. RHE) (around the flat-band potential), the spectrum exhibits a positive absorption at $580 \mathrm{~nm}$, which rapidly decays within a few ms due to fast electron-hole recombination. As the applied bias anodically shifts from 0.8 to $1.6 \mathrm{~V}$, the TA lifetime notably increases by three orders of magnitude. A broad, long-lived absorption centered at approximately $650 \mathrm{~nm}$ and a narrow, negative bleaching at $580 \mathrm{~nm}$ can also be noticed. To gain insights into these origins, TA profiles at different applied biases were further probed at 650 and $580 \mathrm{~nm}$. In Figure 7B, the TA absorption at $650 \mathrm{~nm}$ exhibits biphasic decay kinetics at a bias more anodic than $0.8 \mathrm{~V}$. A fast decay component is observed at a timescale $<10 \mathrm{~ms}$, followed by a slow decay feature beyond $10 \mathrm{~ms}$. The fast decay component can be attributed to electron-hole recombination, which is suppressed under more anodic bias conditions. The depressed charge recombination is due to the formation of a depletion layer rendered by the applied bias. However, the slow decay term can be attributed to the formation of long-lived photoholes. In Figure 7C, the TA bleaching at $580 \mathrm{~nm}$ can be ascribed to the electronic transition from the valence band to the shallow localized states below the conduction band. Note that the negative bleaching reflects a photoelectron trapping event at these intraband states, while the positive absorption corresponds to a photohole trapping process. At $0.5 \mathrm{~V}$, a nearly unbiased condition, the intraband states are filled with electrons and thus function as photohole traps. Upon UV excitation, the rapid photohole trapping process induces an ESA, producing positive TA signals at $580 \mathrm{~nm}$ observed at $0.5 \mathrm{~V}$. Under anodic bias conditions ( 0.8 to $1.6 \mathrm{~V}$ ), these intraband states are oxidized to become electron traps. The trapping of photoelectrons on the intraband states then give rise to negative TA bleaching signals.

The origins of the two TA signals at 650 and $580 \mathrm{~nm}$ are depicted in Figure 7D. Attention was first given to the long-lived absorption feature at $650 \mathrm{~nm}$. Under an anodic bias condition, a depletion layer was formed at the photoanode surface, which facilitated charge carrier separation to enable photohole accumulation. The recorded long-lived TA absorption with a considerably long lifetime (>1 s) supported the argument. Figure 7E further shows the correlation between the amplitude of the slow decay term at $650 \mathrm{~nm}$ and the PEC activity of the $\alpha-\mathrm{Fe}_{2} \mathrm{O}_{3}$ photoanode under different applied biases. The two traces exhibited a similar onset potential and a bias-dependent relation. This consistency confirmed that the slow decay term at $650 \mathrm{~nm}$ under an anodic bias resulted from the long-lived photoholes, which was decisive to the water oxidation activity. On the other hand, the TA bleaching at $580 \mathrm{~nm}$ under different applied biases was also analyzed. In Figure 7F, the amplitude of the bleaching at $580 \mathrm{~nm}$ was found to increase with the square root of the applied bias. This relation is similar to the square-dependence of the depletion layer thickness on the potential drop across the depletion layer [97]. Such a similarity demonstrates that the TA bleaching at $580 \mathrm{~nm}$ derived from charge carrier generation within the depletion layer. Figure $7 \mathrm{G}$ depicts the conceived charge dynamics mechanism of the $\alpha-\mathrm{Fe}_{2} \mathrm{O}_{3}$ photoanode at different anodic biases. At $0.5 \mathrm{~V}$, a nearly unbiased condition, the Fermi level of $\alpha-\mathrm{Fe}_{2} \mathrm{O}_{3}$ is close to the conduction band edge, resulting in electron donation to the intraband trap states. Upon photoexcitation, the photoholes are rapidly captured by these states $(<1 \mu \mathrm{s})$, resulting in the positive TA absorption signals at $580 \mathrm{~nm}$. This TA absorption rapidly decays as the photoelectrons are subject to recombination with the trapped photoholes. At $1.1 \mathrm{~V}$, a moderate bias, a depletion layer is formed at the photoanode surface, sweeping out the trapped photoelectrons and emptying the intraband trap states inside the depletion layer. Under this situation, the intraband states serve as electron traps, capturing photoelectrons $(<1 \mathrm{~ms})$ to cause TA bleaching. The trapped photoelectrons subsequently recombine with the photoholes on the ms timescale. At $1.6 \mathrm{~V}$, a highly anodic bias, the strong built-in field drifted most of the trapped photoelectrons to the external circuit. Therefore, the photoholes at the valence band accumulate and diffuse to the photoanode surface, driving water oxidation reactions on the timescale of a few seconds. 


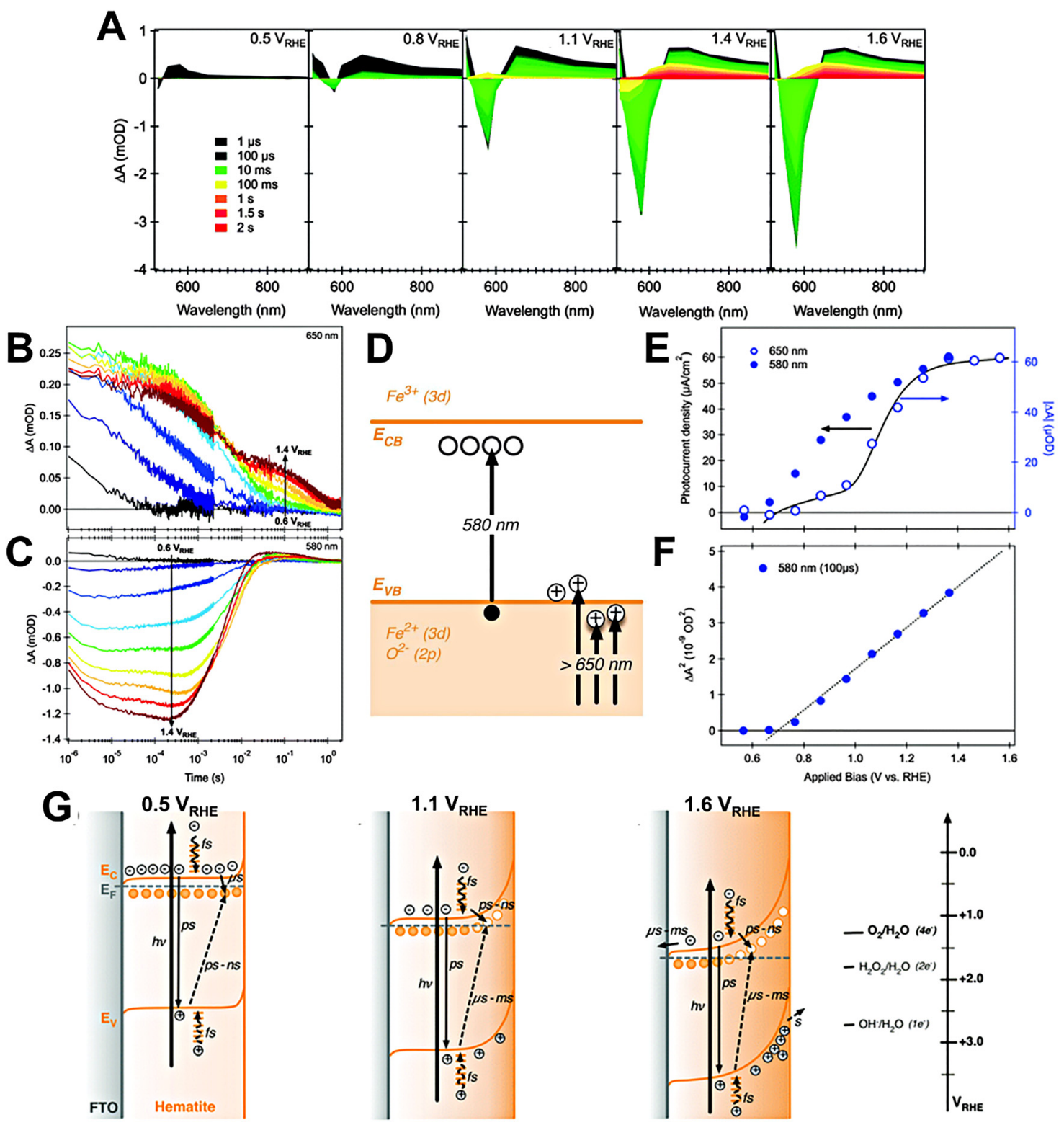

Figure 7: (A) In situ transient absorption (TA) spectra of Si-doped $\alpha-\mathrm{Fe}_{2} \mathrm{O}_{3}$ photoanode at different applied biases after UV excitation ( $355 \mathrm{~nm}$, $200 \mu \mathrm{cm}^{-2}$ ). (B, C) TA profiles at $650 \mathrm{~nm}$ (b panel) and $580 \mathrm{~nm}$ (C panel) at different applied biases. (D) Origins of the two TA signals at 650 and $580 \mathrm{~nm}$. (E) Correlation between the photocurrent and TA amplitude at 650 and $580 \mathrm{~nm}$ at $100 \mathrm{~ms}$ after UV excitation under different applied biases. (F) Dependence of the square of the TA amplitude at $580 \mathrm{~nm}$ and $100 \mu \mathrm{s}$ after UV excitation on the applied bias. (G) Proposed charge dynamics mechanism of $\alpha-\mathrm{Fe}_{2} \mathrm{O}_{3}$ under different applied biases. Reprinted with permission from a study by Barroso et al. [47]. Copyright 2013 Royal Society of Chemistry.

\section{Photocatalytic systems}

Literature regarding the use of in situ TA spectroscopy to investigate photocatalytic systems is relatively scarce. Here, we introduce two representative works that employed in situ TA spectroscopy to explore the charge dynamics of nanosized $\mathrm{Cu}_{2} \mathrm{O}$ [98] and $\mathrm{TiO}_{2}$ photocatalysts [99]. A compendious discussion on the implications of charge dynamics in photocatalytic reactions is also presented.

\section{1 $\mathrm{Cu}_{2} \mathrm{O}$ photocatalysts}

As a p-type semiconductor, $\mathrm{Cu}_{2} \mathrm{O}$ offers a narrow direct bandgap $\left(E_{\mathrm{g}}=2.0-2.2 \mathrm{eV}\right)[100,101]$ and an appropriate band structure $\left(E_{\mathrm{CB}}=-1.08\right.$ vs. $\mathrm{NHE} ; E_{\mathrm{VB}}=+0.93 \mathrm{~V}$ vs. NHE) [102] suitable for various solar-driven photocatalytic applications. Since Tennakone et al. [103] first demonstrated photocatalytic carbon dioxide reduction on $\mathrm{Cu}_{2} \mathrm{O}$ in 1989, $\mathrm{Cu}_{2} \mathrm{O}$ has been an appealing visible-responsive 

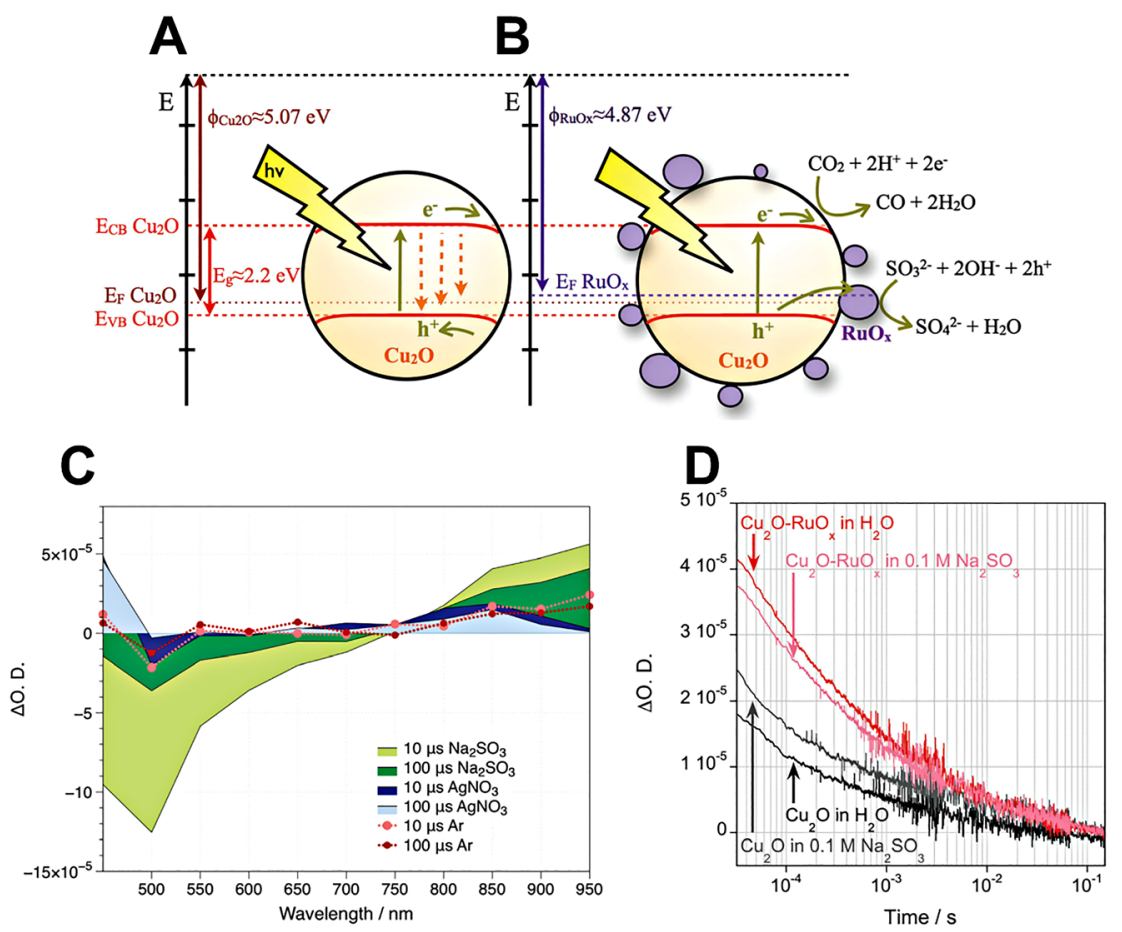

Figure 8: $(A, B)$ Proposed charge dynamics mechanism of pure $\mathrm{Cu}_{2} \mathrm{O}$ (A panel) and $\mathrm{Cu}_{2} \mathrm{O} / \mathrm{RuO}_{x}$ (B panel). (C) In situ transient absorption (TA) spectra of pure $\mathrm{Cu}_{2} \mathrm{O}$ in an Ar-purged electrolyte with the addition of $0.1 \mathrm{M} \mathrm{Na}_{2} \mathrm{SO}_{3}$ or $0.1 \mathrm{M} \mathrm{AgNO}_{3}$ at 10 and $100 \mu \mathrm{s}$ after UV excitation ( $355 \mathrm{~nm}$, $1.2 \mathrm{~mJ} \mathrm{~cm}{ }^{-2}$ ). (D) TA profiles of photoelectrons $(950 \mathrm{~nm})$ for pure $\mathrm{Cu}_{2} \mathrm{O}$ and $\mathrm{Cu}_{2} \mathrm{O} /$ $\mathrm{RuO}_{x}$ in an Ar-purged electrolyte with the addition of $0.1 \mathrm{M} \mathrm{Na}_{2} \mathrm{SO}_{3}$. Reprinted with permission from a study by Pastor et al. [98]. Copyright 2014 Royal Society of Chemistry. photocatalyst for converting greenhouse gases into valueadded chemicals. However, the stability of $\mathrm{Cu}_{2} \mathrm{O}$ has been a concern, since it can be easily oxidized or reduced by photoexcited charge carriers. Additionally, for $p$-type $\mathrm{Cu}_{2} \mathrm{O}$, the downward band bending at the $\mathrm{Cu}_{2} \mathrm{O} /$ electrolyte would obstruct the photohole transfer to the surface, which would hinder the oxidation reaction. As depicted in Figure 8A, the overall photocatalytic performance is then restrained by electron-hole recombination induced by trapped photoholes. To achieve practical use of $\mathrm{Cu}_{2} \mathrm{O}$ photocatalysts, appropriate surface modification to mediate interfacial charge dynamics is indispensable. Pastor et al. [98] reported a visible light-driven photocatalytic carbon dioxide reduction system by using $\mathrm{RuO}_{x}$-deposited $\mathrm{Cu}_{2} \mathrm{O}$ films $\left(\mathrm{Cu}_{2} \mathrm{O} / \mathrm{RuO}_{x}\right)$ as a photocatalyst. After the deposition of cocatalyst $\mathrm{RuO}_{x}$, the photoelectron lifetime of $\mathrm{Cu}_{2} \mathrm{O}$ was prolonged and the carbon dioxide reduction performance was improved. As illustrated in Figure 8B, $\mathrm{RuO}_{x}$ was deposited on the surface of $\mathrm{Cu}_{2} \mathrm{O}$ in order to extract photoholes from the valence band. The yield of long-lived photoelectrons can be increased due to the suppression of electron-hole recombination. In situ TA spectroscopy was performed for the purpose of realizing the charge carrier dynamics of $\mathrm{Cu}_{2} \mathrm{O} / \mathrm{RuO}_{x}$. Pure $\mathrm{Cu}_{2} \mathrm{O}$ film was first measured in an $\mathrm{Ar}-$ purged electrolyte under different experimental conditions (with the addition of an $\mathrm{Na}_{2} \mathrm{SO}_{3}$ as hole scavenger or $\mathrm{AgNO}_{3}$ as electron scavenger). In Figure 8C, the TA spectra of $\mathrm{Cu}_{2} \mathrm{O}$ without adding an electron/hole scavenger exhibited a broad negative bleaching from 475 to $750 \mathrm{~nm}$ and two positive absorption signals below $475 \mathrm{~nm}$ and beyond $800 \mathrm{~nm}$. The magnitude of the positive signal was increased beyond $850 \mathrm{~nm}$ by the addition of an $\mathrm{Na}_{2} \mathrm{SO}_{3}$ hole scavenger and decreased by the introduction of $\mathrm{AgNO}_{3}$ electron scavenger. Therefore, the absorption beyond $850 \mathrm{~nm}$ can be attributed to the photoelectrons of $\mathrm{Cu}_{2} \mathrm{O}$. Similarly, the absorption below $475 \mathrm{~nm}$ was ascribed to the photoholes of $\mathrm{Cu}_{2} \mathrm{O}$ since it was largely enhanced by the addition of an $\mathrm{AgNO}_{3}$ electron scavenger. Note that such electron/hole scavenging processes were ultrafast $(<10 \mu \mathrm{s})$ because the corresponding TA signals already emerged at $10 \mu$ s after UV excitation.

The effects of $\mathrm{RuO}_{x}$ deposition on the charge dynamics of $\mathrm{Cu}_{2} \mathrm{O}$ were further examined. In Figure 8D, the TA profiles of photoelectrons at $950 \mathrm{~nm}$ for pure $\mathrm{Cu}_{2} \mathrm{O}$ and $\mathrm{Cu}_{2} \mathrm{O} / \mathrm{RuO}_{x}$ are compared. For pure $\mathrm{Cu}_{2} \mathrm{O}$, the addition of $\mathrm{Na}_{2} \mathrm{SO}_{3}$ only caused a fairly limited increase in the TA amplitude, suggesting that photohole scavenging was ineffective as a result of a pronounced charge recombination. With the deposition of $\mathrm{RuO}_{\mathrm{x}}$, the TA amplitude was largely increased, regardless of $\mathrm{Na}_{2} \mathrm{SO}_{3}$ addition, indicating an effective suppression of charge recombination. It can be concluded that $\mathrm{RuO}_{x}$ deposition can serve as a hole acceptor to facilitate photohole transfer from $\mathrm{Cu}_{2} \mathrm{O}$ to $\mathrm{RuO}_{x}$. This charge dynamics mediation increases the yield of long-loved photoelectrons for $\mathrm{Cu}_{2} \mathrm{O}(>100 \mu \mathrm{s})$, expediting 


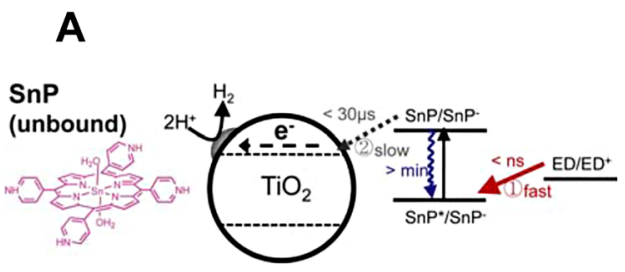

B

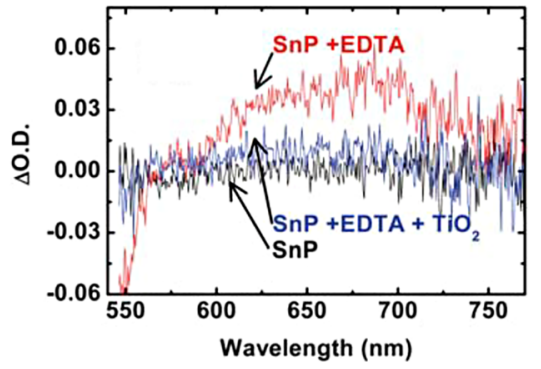

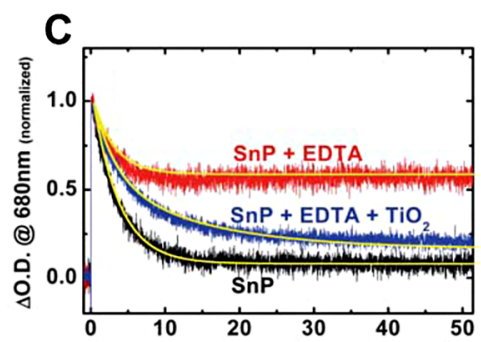

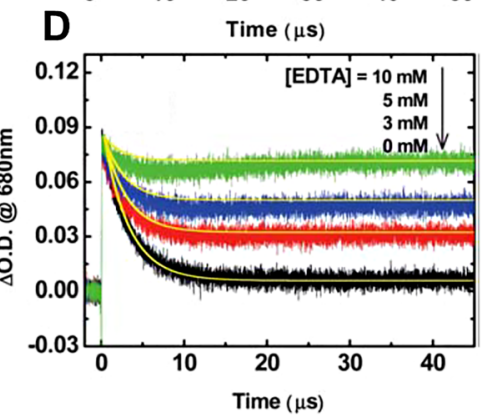

Figure 9: (A) Proposed charge dynamics mechanism of SnP-sensitized $\mathrm{TiO}_{2}$. (B) In situ transient absorption (TA) spectra for $\mathrm{SnP}, \mathrm{SnP}+\mathrm{EDTA}$ and $\mathrm{SnP}+\mathrm{EDTA}+\mathrm{TiO}_{2}$ at $30 \mu$ s after visible excitation ( $532 \mathrm{~nm}$ ). (C) TA profiles at $680 \mathrm{~nm}$ for SnP, SnP + EDTA and $\mathrm{SnP}+\mathrm{EDTA}+\mathrm{TiO}_{2}$. (D) TA profiles at $680 \mathrm{~nm}$ for SnP + EDTA under different EDTA concentrations. Reprinted with permission from a study by Kim et al. [99]. Copyright 2010 Royal Society of Chemistry. the oxidation reaction kinetics to improve the overall photocatalytic activity.

\subsection{Dye-sensitized $\mathrm{TiO}_{2}$ photocatalysts}

Among the different semiconductor photocatalysts, $\mathrm{TiO}_{2}$ is the most extensive photocatalyst for carbon dioxide reduction by virtue of its good stability, nontoxicity, and low price of production. Additionally, the intrinsic oxygen vacancy can activate carbon dioxide molecules in dark and irradiation conditions, making $\mathrm{TiO}_{2}$ an attractive photocatalyst candidate for carbon dioxide reduction [104]. Kim et al. reported a tin porphyrin (SnP)-sensitized $\mathrm{TiO}_{2}$ photocatalyst and studied the charge dynamics mechanism associated with hydrogen production by employing in situ TA spectroscopy [99]. The general reaction mechanism is plotted in Figure 9A. In this sensitized photocatalytic system, $\mathrm{SnP}$ is first excited by visible light to produce the triplet state ${ }^{3} \mathrm{SnP}^{\star}$, which then receives electrons from the ED, ethylenediaminetetraacetic acid (EDTA), to become SnP. ${ }^{-}$. Afterward, an interfacial electron transfer from $\mathrm{SnP}^{-}$to the conduction band of $\mathrm{TiO}_{2}$ occurs. Finally, a hydrogen production reaction takes place at $\mathrm{TiO}_{2}$ at the expense of the separated electrons. It is worth mentioning that $\mathrm{SnP}$ was not chemically attached to the $\mathrm{TiO}_{2}$ surface. Therefore, whether or not the electrons of ED can swiftly transfer to the reactive sites of $\mathrm{TiO}_{2}$ determines the photocatalytic activity. Figure 9B compares the in situ TA profiles spectra for SnP, SnP/EDTA, and SnP/EDTA/ $\mathrm{TiO}_{2}$ at $30 \mu$ s after visible excitation. SnP itself did not show substantial TA signals because of the fast charge recombination $(<30 \mu \mathrm{s})$. In the presence of EDTA as ED, the collected TA profile showed a positive absorption signal at $680 \mathrm{~nm}$, which could be assigned to $\mathrm{SnP}^{-}$as a result of the electron transfer from ED to ${ }^{3} \mathrm{SnP}^{\star}$. This positive TA signal was depressed upon the addition of $\mathrm{TiO}_{2}$, which could be accounted for by the electron transfer from SnP.to $\mathrm{TiO}_{2}$. Figure $9 \mathrm{C}$ further shows the TA profiles collected at $680 \mathrm{~nm}$ for the three cases. SnP itself decays within $10 \mu \mathrm{s}$. For SnP + EDTA, the decay of the TA absorption was significantly retarded, the degree of which became more pronounced with an increasing EDTA concentration (as shown in Figure 9D). This feature reflects the production of long-lived $\mathrm{SnP} \bullet^{-}$, which can survive for minutes. However, for SnP + EDTA + $\mathrm{TiO}_{2}$, the TA absorption decay was accelerated to reach a lifetime $<30 \mu \mathrm{s}$. Effective hydrogen production was achieved on the present SnP-sensitized $\mathrm{TiO}_{2}$ system, even though $\mathrm{SnP}$ was not chemically attached to $\mathrm{TiO}_{2}$. The success was made possible because the lifetime of $\mathrm{SnP}^{-}$- was sufficiently long to enable an interfacial electron transfer to $\mathrm{TiO}_{2}$ for hydrogen production.

\section{Summary and perspectives}

Interfacial charge dynamics play a pivotal role in governing the solar-to-fuel efficiency of semiconductor nanostructures in PEC and photocatalytic reactions. In situ TA spectroscopy allows for the veritable charge dynamics mechanism of samples under PEC and photocatalytic operating conditions to be elucidated. In this Review, we summarized the recent efforts of using in situ TA to perform real-time observations of interfacial charge dynamics for representative photoelectrodes $\left(\mathrm{TiO}_{2}, \mathrm{BiVO}_{4}, \mathrm{WO}_{3}\right.$, $\left.\alpha-\mathrm{Fe}_{2} \mathrm{O}_{3}\right)$ and photocatalysts $\left(\mathrm{Cu}_{2} \mathrm{O}, \mathrm{TiO}_{2}\right)$. Although great 
progress has been made, there is substantial room for further advancement. For example, the majority of the studied photoelectrodes is of the photoanode type made of $n$-type semiconductors. Few studies are available on realtime observations of charge dynamics for $p$-type semiconductor photocathodes [51]. Compared to the plentiful examples of the studied photoelectrodes, research is relatively scarce on the topic of exploring the in situ charge dynamics of photocatalysts. Continuous efforts must be made in an attempt to acquire the true charge dynamics mechanism of semiconductor nanostructures for photocatalytic reactions, especially for carbon dioxide reduction, which is an ideal and practical platform for realizing artificial photosynthesis.

Compared with other ultrafast spectroscopic systems, for example, time-resolved photoluminescence, TA spectroscopy with the temporal resolution down to fs can serve as a more reliable tool to analyze ultrafast charge dynamics, such as charge trapping and detrapping processes, which lie in the fs to ps timescale [105, 106]. In particular, the trapped charge carriers can be directly detected by TA because of their strong transient optical absorption. This feature makes TA perfectly suited for the analysis of ultrafast charge dynamics. Undoubtedly, using in situ TA to intuitively monitor interfacial charge dynamics of semiconductor nanostructures can provide links to the actual charge transfer scenarios for optimizing PEC and photocatalytic systems. However, the spectroscopic setup of in situ TA is still divergent from the experimental conditions of practical PEC and photocatalytic reactions. For example, in situ TA uses a pulsed laser as an excitation source, while real PEC and photocatalytic systems operate under continuous irradiation. Concerns are also raised by the variant charge transfer behaviors as a result of the exceeding laser power of TA. The charge transfer scenarios derived from the in situ TA setup are therefore likely to be defective. In this regard, introducing continuous illumination into the time-resolved spectroscopic setup [107] can allow for probing interfacial charge dynamics in a perfectly compliant manner. Such an operando spectroscopic measurement is of essential significance and can offer more reliable information on the charge dynamics mechanism for working photoelectrodes and photocatalysts. Future utilization of this technique will benefit from the ongoing development of more sophisticated materials systems, such as single atom-based photoelectrodes [108] and photocatalysts [109], for advanced PEC and photocatalytic applications.
Acknowledgments: Y.-J. H. also acknowledges the budget support from the Center for Emergent Functional Matter Science of National Chiao Tung University from The Featured Areas Research Center Program within the framework of the Higher Education Sprout Project by the Ministry of Education in Taiwan.

Author contribution: All the authors have accepted responsibility for the entire content of this submitted manuscript and approved submission.

Research funding: This work was financially supported by the Ministry of Science and Technology (MOST) of Taiwan under grants MOST 108-2628-M-009-004-MY3, MOST 1082218-E-009-039-MY3 and MOST 109-2923-M-009-003-MY2. Conflict of interest statement: The authors declare no conflicts of interest regarding this article.

\section{References}

[1] P. Pan, S. P. Wu, Y. Xiao, and G. Liu, "A review on hydronic asphalt pavement for energy harvesting and snow melting," Renew. Sustain. Energy Rev., vol. 48, pp. 624-634, 2015.

[2] M. Smyth, G. Barone, A. Buonomano, et al., "Modelling and experimental evaluation of an innovative integrated collector storage solar water heating (ICSSWH) prototype," Renew. Energy, vol. 157, pp. 974-986, 2020.

[3] A. Lenert, D. M. Bierman, Y. Nam, et al., "A nanophotonic solar thermophotovoltaic device," Nat. Nanotechnol., vol. 9, no. 2, pp. 126-130, 2014.

[4] Y. T. Jia, G. Alva, and G. Y. Fang, "Development and applications of photovoltaic-thermal systems: a review," Renew. Sustain. Energy Rev., vol. 102, pp. 249-265, 2019.

[5] Y. G. Rong, Y. Hu, A. Y. Mei, et al.., "Challenges for commercializing perovskite solar cells," Science, vol. 361, no. 6408, p. 7, 2018.

[6] A. K. Jena, A. Kulkarni, and T. Miyasaka, "Halide perovskite photovoltaics: background, status, and future prospects," Chem. Rev., vol. 119, no. 5, pp. 3036-3103, 2019.

[7] B. You and Y. J. Sun, "Innovative strategies for electrocatalytic water splitting," Acc. Chem. Res., vol. 51, no. 7, pp. 1571-1580, 2018.

[8] J. Zhu, L. S. Hu, P. X. Zhao, L. Y. S. Lee, and K. Y. Wong, “Recent advances in electrocatalytic hydrogen evolution using nanoparticles," Chem. Rev., vol. 120, no. 2, pp. 851-918, 2020.

[9] X. X. Zou and Y. Zhang, "Noble metal-free hydrogen evolution catalysts for water splitting," Chem. Soc. Rev., vol. 44, no. 15, pp. 5148-5180, 2015.

[10] Z. Wang, C. Li, and K. Domen, "Recent developments in heterogeneous photocatalysts for solar-driven overall water splitting," Chem. Soc. Rev., vol. 48, no. 7, pp. 2109-2125, 2019.

[11] G. Centi, E. A. Quadrelli, and S. Perathoner, "Catalysis for $\mathrm{CO}_{2}$ conversion: a key technology for rapid introduction of renewable energy in the value chain of chemical industries," Energy Environ. Sci., vol. 6, no. 6, pp. 1711-1731, 2013. 
[12] H. Takeda, C. Cometto, O. Ishitani, and M. Robert, "Electrons, photons, protons and earth-abundant metal complexes for molecular catalysis of $\mathrm{CO}_{2}$ reduction," ACS Catal., vol. 7, no. 1, pp. 70-88, 2017.

[13] O. Khaselev and J. A. Turner, "A monolithic photovoltaicphotoelectrochemical device for hydrogen production via water splitting," Science, vol. 280, no. 5362, pp. 425-427, 1998.

[14] T. Hisatomi, J. Kubota, and K. Domen, "Recent advances in semiconductors for photocatalytic and photoelectrochemical water splitting," Chem. Soc. Rev., vol. 43, no. 22, pp. 7520-7535, 2014.

[15] A. Kudo and Y. Miseki, "Heterogeneous photocatalyst materials for water splitting," Chem. Soc. Rev., vol. 38, no. 1, pp. 253-278, 2009.

[16] W. H. Wang, Y. Himeda, J. T. Muckerman, G. F. Manbeck, and E. Fujita, " $\mathrm{CO}_{2}$ hydrogenation to formate and methanol as an alternative to photo- and electrochemical $\mathrm{CO}_{2}$ reduction," Chem. Rev., vol. 115, no. 23, pp. 12936-12973, 2015.

[17] W. G. Tu, Y. Zhou, and Z. G. Zou, "Photocatalytic conversion of $\mathrm{CO}_{2}$ into renewable hydrocarbon fuels: state-of-the-art accomplishment, challenges, and prospects," Adv. Mater., vol. 26, no. 27, pp. 4607-4626, 2014.

[18] G. W. Cui, X. L. Yang, Y. J. Zhang, et al., "Round-the-clock photocatalytic hydrogen production with high efficiency by a long-afterglow material," Angew. Chem. Int. Ed., vol. 58, no. 5, pp. 1340-1344, 2019.

[19] A. T. Garcia-Esparza and K. Takanabe, “A simplified theoretical guideline for overall water splitting using photocatalyst particles," J Mater Chem A, vol. 4, no. 8, pp. 2894-2908, 2016.

[20] M. Ni, M. K. H. Leung, D. Y. C. Leung, and K. Sumathy, “A review and recent developments in photocatalytic water-splitting using $\mathrm{TiO}_{2}$ for hydrogen production," Renew. Sustain. Energy Rev., vol. 11, no. 3, pp. 401-425, 2007.

[21] J. Low, J. Yu, M. Jaroniec, S. Wageh, and A. A. Al-Ghamdi, "Heterojunction photocatalysts," Adv. Mater., vol. 29, no. 20, p. 1601694, 2017.

[22] S. H. Shen, S. A. Lindley, X. Y. Chen, and J. Z. Zhang, "Hematite heterostructures for photoelectrochemical water splitting: rational materials design and charge carrier dynamics," Energy Environ. Sci., vol. 9, no. 9, pp. 2744-2775, 2016.

[23] J. H. Yang, D. G. Wang, H. X. Han, and C. Li, "Roles of cocatalysts in photocatalysis and photoelectrocatalysis," Acc. Chem. Res., vol. 46, no. 8, pp. 1900-1909, 2013.

[24] Z. S. Li, W. J. Luo, M. L. Zhang, J. Y. Feng, and Z. G. Zou, "Photoelectrochemical cells for solar hydrogen production: current state of promising photoelectrodes, methods to improve their properties, and outlook," Energy Environ. Sci., vol. 6, no. 2, pp. 347-370, 2013.

[25] Y. C. Zhang, H. W. Ji, W. H. Ma, C. C. Chen, W. J. Song, and J. C. Zhao, "Doping-promoted solar water oxidation on hematite photoanodes," Molecules, vol. 21, no. 7, p. 15, 2016.

[26] Y. C. Qiu, K. Y. Yan, H. Deng, and S. H. Yang, "Secondary branching and nitrogen doping of $\mathrm{ZnO}$ nanotetrapods: building a highly active network for photoelectrochemical water splitting," Nano Lett., vol. 12, no. 1, pp. 407-413, 2012.

[27] P. V. Kamat, "Photochemistry on nonreactive and reactive (semiconductor) surfaces," Chem. Rev., vol. 93, no. 1, pp. 267-300, 1993.
[28] A. Mills and S. Lehunte, "An overview of semiconductor photocatalysis," J. Photochem. Photobiol. A, vol. 108, no. 1, pp. 1-35, 1997.

[29] M. Mikkelsen, M. Jorgensen, and F. C. Krebs, "The teraton challenge. A review of fixation and transformation of carbon dioxide," Energy Environ. Sci., vol. 3, no. 1, pp. 43-81, 2010.

[30] S. N. Habisreutinger, L. Schmidt-Mende, and J. K. Stolarczyk, "Photocatalytic reduction of $\mathrm{CO}_{2}$ on $\mathrm{TiO}_{2}$ and other semiconductors," Angew. Chem. Int. Ed., vol. 52, no. 29, pp. 7372-7408, 2013.

[31] X. X. Chang, T. Wang, and J. L. Gong, “ $\mathrm{CO}_{2}$ photo-reduction: insights into $\mathrm{CO}_{2}$ activation and reaction on surfaces of photocatalysts," Energy Environ. Sci., vol. 9, no. 7, pp. 2177-2196, 2016.

[32] J. Y. Xu, X. Tong, P. Yu, et al., "Ultrafast dynamics of charge transfer and photochemical reactions in solar energy conversion," Adv. Sci., vol. 5, no. 12, p. 18, 2018.

[33] X. H. Chen, K. Wang, and M. C. Beard, "Ultrafast probes at the interfaces of solar energy conversion materials," Phys. Chem. Chem. Phys., vol. 21, no. 30, pp. 16399-16407, 2019.

[34] R. Berera, R. Van Grondelle, and J. T. M. Kennis, "Ultrafast transient absorption spectroscopy: principles and application to photosynthetic systems," Photosynth. Res., vol. 101, nos. 2-3, pp. 105-118, 2009.

[35] R. Berera, R. Van Grondelle, and J. T. M. Kennis, "Ultrafast transient absorption spectroscopy: principles and application to photosynthetic systems," Photosynth. Res., vol. 101, no. 2, pp. 105-118, 2009.

[36] Q. Zhang and Y. Luo, "Probing the ultrafast dynamics in nanomaterial complex systems by femtosecond transient absorption spectroscopy," High Power Laser Sci Eng., vol. 4, p. e22, 2016.

[37] A. Kafizas, Y. M. Ma, E. Pastor, et al., "Water oxidation kinetics of accumulated holes on the surface of a $\mathrm{TiO}_{2}$ photoanode: a rate law analysis," ACS Catal., vol. 7, no. 7, pp. 4896-4903, 2017.

[38] A. J. Cowan, J. W. Tang, W. H. Leng, J. R. Durrant, and D. R. Klug, "Water splitting by nanocrystalline $\mathrm{TiO}_{2}$ in a complete photoelectrochemical cell exhibits efficiencies limited by charge recombination," J. Phys. Chem. C, vol. 114, no. 9, pp. 4208-4214, 2010.

[39] F. M. Pesci, G. M. Wang, D. R. Klug, Y. Li, and A. J. Cowan, "Efficient suppression of electron hole recombination in oxygendeficient hydrogen-treated $\mathrm{TiO}_{2}$ nanowires for photoelectrochemical water splitting," J. Phys. Chem. C, vol. 117, no. 48, pp. 25837-25844, 2013.

[40] A. J. Cowan, W. H. Leng, P. R. F. Barnes, D. R. Klug, and J. R. Durrant, "Charge carrier separation in nanostructured $\mathrm{TiO}_{2}$ photoelectrodes for water splitting," Phys. Chem. Chem. Phys., vol. 15, no. 22, pp. 8772-8778, 2013.

[41] S. Selim, E. Pastor, M. Garcia-Tecedor, et al., "Impact of oxygen vacancy occupancy on charge carrier dynamics in $\mathrm{BiVO}_{4}$ photoanodes," J. Am. Chem. Soc., vol. 141, no. 47, pp. 18791-18798, 2019.

[42] K. Zhang, B. J. Jin, C. Park, et al., "Black phosphorene as a hole extraction layer boosting solar water splitting of oxygen evolution catalysts," Nat. Commun., vol. 10, p. 10, 2019.

[43] S. Corby, L. Francas, A. Kafizas, and J. R. Durrant, "Determining the role of oxygen vacancies in the photoelectrocatalytic performance of $\mathrm{WO}_{3}$ for water oxidation," Chem. Sci., vol. 11, no. 11, pp. 2907-2914, 2020. 
[44] W. Kim, T. Tachikawa, D. Monllor-Satoca, H. I. Kim, T. Majima, and W. Choi, "Promoting water photooxidation on transparent $\mathrm{WO}_{3}$ thin films using an alumina overlayer," Energy Environ. Sci., vol. 6, no. 12, pp. 3732-3739, 2013.

[45] S. Corby, L. Francas, S. Selim, et al., "Water oxidation and electron extraction kinetics in nanostructured tungsten trioxide photoanodes," J. Am. Chem. Soc., vol. 140, no. 47, pp. 16168-16177, 2018.

[46] Y. Yang, M. Forster, Y. C. Ling, et al., “Acid treatment enables suppression of electron-hole recombination in hematite for photoelectrochemical water splitting," Angew. Chem. Int. Ed., vol. 55, no. 10, pp. 3403-3407, 2016.

[47] M. Barroso, S. R. Pendlebury, A. J. Cowan, and J. R. Durrant, "Charge carrier trapping, recombination and transfer in hematite $\left(\alpha-\mathrm{Fe}_{2} \mathrm{O}_{3}\right)$ water splitting photoanodes," Chem. Sci., vol. 4, no. 7, pp. 2724-2734, 2013.

[48] M. Forster, R. J. Potter, Y. C. Ling, et al., “Oxygen deficient $\alpha-\mathrm{Fe}_{2} \mathrm{O}_{3}$ photoelectrodes: a balance between enhanced electrical properties and trap-mediated losses," Chem. Sci., vol. 6, no. 7, pp. 4009-4016, 2015.

[49] F. Le Formal, S. R. Pendlebury, M. Cornuz, S. D. Tilley, M. Gratzel, and J. R. Durrant, "Back electron-hole recombination in hematite photoanodes for water splitting," J. Am. Chem. Soc., vol. 136, no. 6, pp. 2564-2574, 2014.

[50] E. Pastor, J. S. Park, L. Steier, et al., "In situ observation of picosecond polaron self-localisation in $\alpha-\mathrm{Fe}_{2} \mathrm{O}_{3}$ photoelectrochemical cells," Nat. Commun., vol. 10, p. 7, 2019.

[51] X. Q. Xiong, M. Forster, J. D. Major, Y. M. Xu, and A. J. Cowan, "Time-resolved spectroscopy of ZnTe photocathodes for solar fuel production," J. Phys. Chem. C, vol. 121, no. 40, pp. 22073-22080, 2017.

[52] A. Fujishima and K. Honda, "Electrochemical photolysis of water at a semiconductor electrode," Nature, vol. 238, no. 5358, p. 37, 1972.

[53] Y. C. Pu, G. M. Wang, K. D. Chang, et al., "Au nanostructuredecorated $\mathrm{TiO}_{2}$ nanowires exhibiting photoactivity across entire UV-visible region for photoelectrochemical water splitting," Nano Lett., vol. 13, no. 8, pp. 3817-3823, 2013.

[54] Y. C. Pu, Y. C. Ling, K. D. Chang, et al., "Surface passivation of $\mathrm{TiO}_{2}$ nanowires using a facile precursor-treatment approach for photoelectrochemical water oxidation," J. Phys. Chem. C, vol. 118, no. 27, pp. 15086-15094, 2014.

[55] Y. S. Chang, M. Choi, M. Baek, P. Y. Hsieh, K. Yong, and Y. J. Hsu, "CdS/CdSe co-sensitized brookite $\mathrm{H}: \mathrm{TiO}_{2}$ nanostructures: charge carrier dynamics and photoelectrochemical hydrogen generation," Appl. Catal, B, vol. 225, pp. 379-385, 2018.

[56] J. M. Li, Y. T. Wang, and Y. J. Hsu, "A more accurate, reliable method to evaluate the photoelectrochemical performance of semiconductor electrode without under/over estimation," Electrochim. Acta, vol. 267, pp. 141-149, 2018.

[57] P. Y. Hsieh, Y. H. Chiu, T. H. Lai, M. J. Fang, Y. T. Wang, and Y. J. Hsu, " $\mathrm{TiO}_{2}$ nanowire-supported sulfide hybrid photocatalysts for durable solar hydrogen production," ACS Appl. Mater. Interfaces, vol. 11, no. 3, pp. 3006-3015, 2019.

[58] Y. S. Chang, P. Y. Hsieh, T. F. M. Chang, C. Y. Chen, M. Sone, and Y. J. Hsu, "Incorporating graphene quantum dots to enhance the photoactivity of CdSe-sensitized $\mathrm{TiO}_{2}$ nanorods for solar hydrogen production," J. Mater. Chem. A, vol. 8, no. 28, pp. 13971-13979, 2020.
[59] K. Drew, G. Girishkumar, K. Vinodgopal, and P. V. Kamat, "Boosting fuel cell performance with a semiconductor photocatalyst: $\mathrm{TiO}_{2} /$ Pt-ru hybrid catalyst for methanol oxidation," J. Phys. Chem. B, vol. 109, no. 24, pp. 11851-11857, 2005.

[60] K. Vinodgopal, I. Bedja, and P. V. Kamat, "Nanostructured semiconductor films for photocatalysis. Photoelectrochemical behavior of $\mathrm{SnO}_{2} / \mathrm{TiO}_{2}$ composite systems and its role in photocatalytic degradation of a textile azo dye," Chem. Mater., vol. 8, no. 8, pp. 2180-2187, 1996.

[61] C. Kim, J. T. Kim, K. S. Kim, S. Jeong, H. Y. Kim, and Y. S. Han, "Immobilization of $\mathrm{TiO}_{2}$ on an ITO substrate to facilitate the photoelectrochemical degradation of an organic dye pollutant," Electrochim. Acta, vol. 54, no. 24, pp. 5715-5720, 2009.

[62] E. Kusmierek and E. Chrzescijanska, "Application of $\mathrm{TiO}_{2}-\mathrm{RuO}_{2} / \mathrm{Ti}$ electrodes modified with $\mathrm{WO}_{3}$ in electro- and photoelectrochemical oxidation of acid orange 7 dye," J. Photochem. Photobiol. A, vol. 302, pp. 59-68, 2015.

[63] H. B. Li, J. Li, Q. Xu, and X. Y. Hu, “Poly(3-hexylthiophene) $/ \mathrm{TiO}_{2}$ nanoparticle-functionalized electrodes for visible light and low potential photoelectrochemical sensing of organophosphorus pesticide chlopyrifos," Anal. Chem., vol. 83, no. 24, pp. 9681-9686, 2011.

[64] Y. M. Yan, J. M. Fang, Z. Y. Yang, et al., "Photoelectrochemical oxidation of glucose for sensing and fuel cell applications," Chem. Commun., vol. 49, no. 77, pp. 8632-8634, 2013.

[65] J. Shu, Z. L. Qiu, S. Z. Lv, K. Y. Zhang, and D. P. Tang, "Plasmonic enhancement coupling with defect-engineered $\mathrm{TiO}_{2-x}$ : a mode for sensitive photoelectrochemical biosensing," Anal. Chem., vol. 90, no. 4, pp. 2425-2429, 2018.

[66] N. Hao, R. Hua, S. B. Chen, et al., "Multiple signal-amplification via $\mathrm{Ag}$ and $\mathrm{TiO}_{2}$ decorated 3D nitrogen doped graphene hydrogel for fabricating sensitive label-free photoelectrochemical thrombin aptasensor," Biosens. Bioelectron., vol. 101, pp. 14-20, 2018.

[67] D. Bahnemann, A. Henglein, J. Lilie, and L. Spanhel, “Flash photolysis observation of the absorption spectra of trapped positive holes and electrons in colloidal titanium dioxide," J. Phys. Chem. B, vol. 88, no. 4, pp. 709-711, 1984.

[68] D. W. Bahnemann, M. Hilgendorff, and R. Memming, "Charge carrier dynamics at $\mathrm{TiO}_{2}$ particles: reactivity of free and trapped holes," J. Phys. Chem. B, vol. 101, no. 21, pp. 4265-4275, 1997.

[69] T. Yoshihara, R. Katoh, A. Furube, et al., "Identification of reactive species in photoexcited nanocrystalline $\mathrm{TiO}_{2}$ films by wide-wavelength-range (400-2500 nm) transient absorption spectroscopy," J. Phys. Chem. B, vol. 108, no. 12, pp. 3817-3823, 2004.

[70] T. Yoshihara, Y. Tamaki, A. Furube, M. Murai, K. Hara, and R. Katoh, "Effect of ph on absorption spectra of photogenerated holes in nanocrystalline $\mathrm{TiO}_{2}$ films," Chem. Phys. Lett., vol. 438, nos. 4-6, pp. 268-273, 2007.

[71] J. W. Tang, J. R. Durrant, and D. R. Klug, “Mechanism of photocatalytic water splitting in $\mathrm{TiO}_{2}$. Reaction of water with photoholes, importance of charge carrier dynamics, and evidence for four-hole chemistry," J. Am. Chem. Soc., vol. 130, no. 42, pp. 13885-13891, 2008.

[72] W. H. Leng, P. R. F. Barnes, M. Juozapavicius, B. C. O'regan, and J. R. Durrant, "Electron diffusion length in mesoporous nanocrystalline $\mathrm{TiO}_{2}$ photoelectrodes during water oxidation," J. Phys. Chem. Lett., vol. 1, no. 6, pp. 967-972, 2010. 
[73] Y. H. Chiu, T. H. Lai, C. Y. Chen, et al., "Fully depleted Ti-Nb-Ta$\mathrm{Zr}-\mathrm{O}$ nanotubes: interfacial charge dynamics and solar hydrogen production," ACS Appl. Mater. Interfaces, vol. 10, no. 27, pp. 22997-23008, 2018.

[74] J. M. Li, C. W. Tsao, M. J. Fang, C. C. Chen, C. W. Liu, and Y. J. Hsu, " $\mathrm{TiO}_{2}-\mathrm{Au}-\mathrm{Cu}_{2} \mathrm{O}$ photocathodes: Au-mediated z-scheme charge transfer for efficient solar-driven photoelectrochemical reduction," ACS Appl. Nano Mater., vol. 1, no. 12, pp. 6843-6853, 2018.

[75] J. T. Li, S. K. Cushing, P. Zheng, et al., "Solar hydrogen generation by a $\mathrm{CdS}-\mathrm{Au}-\mathrm{TiO}_{2}$ sandwich nanorod array enhanced with Au nanoparticle as electron relay and plasmonic photosensitizer," J. Am. Chem. Soc., vol. 136, no. 23, pp. 8438-8449, 2014.

[76] J. S. Luo, L. Ma, T. C. He, et al., " $\mathrm{TiO}_{2} /(\mathrm{CdS}, \mathrm{CdSe}, \mathrm{CdSeS})$ nanorod heterostructures and photoelectrochemical properties," J. Phys. Chem. C, vol. 116, no. 22, pp. 11956-11963, 2012.

[77] A. J. Cowan, C. J. Barnett, S. R. Pendlebury, et al., "Activation energies for the rate-limiting step in water photooxidation by nanostructured $\alpha-\mathrm{Fe}_{2} \mathrm{O}_{3}$ and $\mathrm{TiO}_{2}$," J. Am. Chem. Soc., vol. 133, no. 26, pp. 10134-10140, 2011.

[78] Y. Park, K. J. Mcdonald, and K. S. Choi, "Progress in bismuth vanadate photoanodes for use in solar water oxidation," Chem. Soc. Rev., vol. 42, no. 6, pp. 2321-2337, 2013.

[79] M. S. Zhu, Z. C. Sun, M. Fujitsuka, and T. Majima, "Z-scheme photocatalytic water splitting on a $2 \mathrm{D}$ heterostructure of black phosphorus/bismuth vanadate using visible light," Angew. Chem. Int. Ed., vol. 57, no. 8, pp. 2160-2164, 2018.

[80] S. Selim, L. Francas, M. Garcia-Tecedor, et al., " $\mathrm{WO}_{3} / \mathrm{BiVO}_{4}$ : impact of charge separation at the timescale of water oxidation," Chem. Sci., vol. 10, no. 9, pp. 2643-2652, 2019.

[81] F. M. Pesci, A. J. Cowan, B. D. Alexander, J. R. Durrant, and D. R. Klug, "Charge carrier dynamics on mesoporous $\mathrm{WO}_{3}$ during water splitting," J. Phys. Chem. Lett., vol. 2, no. 15, pp. 1900-1903, 2011.

[82] Y. Ma, F. Le Formal, A. Kafizas, S. R. Pendlebury, and J. R. Durrant, "Efficient suppression of back electron/hole recombination in cobalt phosphate surface-modified undoped bismuth vanadate photoanodes," J. Mater. Chem. A, vol. 3, no. 41, pp. 20649-20657, 2015.

[83] L. C. Wang, Y. Wang, Y. Cheng, et al., "Hydrogen-treated mesoporous $\mathrm{WO}_{3}$ as a reducing agent of $\mathrm{CO}_{2}$ to fuels $\left(\mathrm{CH}_{4}\right.$ and $\mathrm{CH}_{3} \mathrm{OH}$ ) with enhanced photothermal catalytic performance," J. Mater. Chem. A, vol. 4, no. 14, pp. 5314-5322, 2016.

[84] G. M. Wang, Y. C. Ling, H. Y. Wang, et al., "Hydrogen-treated $\mathrm{WO}_{3}$ nanoflakes show enhanced photostability," Energy Environ. Sci., vol. 5, no. 3, pp. 6180-6187, 2012.

[85] J. H. Sun, L. X. Sun, X. J. Yang, et al., "Photoanode of coupling semiconductor heterojunction and catalyst for solar pec water splitting," Electrochim. Acta, vol. 331, p. 10, 2020.

[86] S. Hilliard, G. Baldinozzi, D. Friedrich, et al., "Mesoporous thin film $\mathrm{WO}_{3}$ photoanode for photoelectrochemical water splitting: a sol-gel dip coating approach," Sustain. Energy Fuels, vol. 1, no. 1, pp. 145-153, 2017.

[87] C. Janaky, W. Chanmanee, and K. Rajeshwar, "On the substantially improved photoelectrochemical properties of nanoporous $\mathrm{WO}_{3}$ through surface decoration with $\mathrm{RuO}_{2}$," Electrocatalysis, vol. 4, no. 4, pp. 382-389, 2013.
[88] Y. Liu, B. R. Wygant, O. Mabayoie, et al., “Interface engineering and its effect on $\mathrm{WO}_{3}$-based photoanode and tandem cell," ACS Appl. Mater. Interfaces, vol. 10, no. 15, pp. 12639-12650, 2018.

[89] Y. H. Yang, R. R. Xie, Y. Liu, J. Li, and W. Z. Li, “Effect of surface passivation on photoelectrochemical water splitting performance of $\mathrm{WO}_{3}$ vertical plate-like films," Catalysts, vol. 5, no. 4, pp. 2024-2038, 2015.

[90] I. Bedja, S. Hotchandani, and P. V. Kamat, "Photoelectrochemistry of quantized $\mathrm{WO}_{3}$ colloids: electron storage, electrochromic, and photoelectrochromic effects," J. Phys. Chem. B, vol. 97, no. 42, pp. 11064-11070, 1993.

[91] S. Piccinin, "The band structure and optical absorption of hematite $\left(\alpha-\mathrm{Fe}_{2} \mathrm{O}_{3}\right)$ : a first-principles GW-BSE study," Phys. Chem. Chem. Phys., vol. 21, no. 6, pp. 2957-2967, 2019.

[92] S. Gahlawat, N. Rashid, and P. P. Ingole, "N-type $\mathrm{Cu}_{2} \mathrm{O} /$ $\alpha-\mathrm{Fe}_{2} \mathrm{O}_{3}$ heterojunctions by electrochemical deposition: tuning of $\mathrm{Cu}_{2} \mathrm{O}$ thickness for maximum photoelectrochemical performance," Z. Phys. Chem., vol. 232, nos. 9-11, pp. 1551-1566, 2018.

[93] Y. Xu and M. A. Schoonen, "The absolute energy positions of conduction and valence bands of selected semiconducting minerals," Am. Mineral, vol. 85, nos. 3-4, pp. 543-556, 2000.

[94] R. F. G. Gardner, F. Sweett, and D. W. Tanner, "The electrical properties of alpha ferric oxide-II: ferric oxide of high purity," J. Phys. Chem. Solid., vol. 24, no. 10, pp. 1183-1196, 1963.

[95] J. H. Kennedy, "Flatband potentials and donor densities of polycrystalline $\alpha-\mathrm{Fe}_{2} \mathrm{O}_{3}$ determined from Mott-Schottky plots," J. Electrochem. Soc., vol. 125, no. 5, p. 723, 1978.

[96] J. H. Kennedy and K. W. Frese, "Photooxidation of water at $\alpha-\mathrm{Fe}_{2} \mathrm{O}_{3}$ electrodes," J. Electrochem. Soc., vol. 125, no. 5, p. 709, 1978.

[97] W. W. Gärtner, "Depletion-layer photoeffects in semiconductors," Phys. Rev., vol. 116, no. 1, pp. 84-87, 1959.

[98] E. Pastor, F. M. Pesci, A. Reynal, et al., "Interfacial charge separation in $\mathrm{Cu}_{2} \mathrm{O} / \mathrm{RuO}_{x}$ as a visible light driven $\mathrm{CO}_{2}$ reduction catalyst," Phys. Chem. Chem. Phys., vol. 16, no. 13, pp. 5922-5926, 2014.

[99] W. Kim, T. Tachikawa, T. Majima, C. Li, H. J. Kim, and W. Choi, "Tin-porphyrin sensitized $\mathrm{TiO}_{2}$ for the production of $\mathrm{H}_{2}$ under visible light," Energy Environ. Sci., vol. 3, no. 11, pp. 1789-1795, 2010.

[100] F. Schweiner, J. Main, M. Feldmaier, G. Wunner, and C. Uihlein, "Impact of the valence band structure of $\mathrm{Cu}_{2} \mathrm{O}$ on excitonic spectra," Phys. Rev. B, vol. 93, no. 19, p. 195203, 2016.

[101] B. K. Meyer, A. Polity, D. Reppin, et al., "Binary copper oxide semiconductors: from materials towards devices," Phys. Status Solidi B, vol. 249, no. 8, pp. 1487-1509, 2012.

[102] A. A. Dubale, A. G. Tamirat, H.-M. Chen, et al., "A highly stable $\mathrm{CuS}$ and $\mathrm{CuS}-\mathrm{Pt}$ modified $\mathrm{Cu}_{2} \mathrm{O} / \mathrm{CuO}$ heterostructure as an efficient photocathode for the hydrogen evolution reaction," J. Mater. Chem. A, vol. 4, no. 6, pp. 2205-2216, 2016.

[103] K. Tennakone, A. H. Jayatissa, and S. Punchihewa, "Selective photoreduction of carbon dioxide to methanol with hydrous cuprous oxide," J. Photochem. Photobiol. A, vol. 49, no. 3, pp. 369-375, 1989. 
[104] L. Liu, H. Zhao, J. M. Andino, and Y. Li, "Photocatalytic $\mathrm{CO}_{2}$ reduction with $\mathrm{H}_{2} \mathrm{O}$ on $\mathrm{TiO}_{2}$ nanocrystals: comparison of anatase, rutile, and brookite polymorphs and exploration of surface chemistry," ACS Catal., vol. 2, no. 8, pp. 1817-1828, 2012.

[105] R. Qian, H. Zong, J. Schneider, et al., “Charge carrier trapping, recombination and transfer during $\mathrm{TiO}_{2}$ photocatalysis: An overview," Catal. Today, vol. 335, pp. 78-90, 2019.

[106] L. Zhang, H. H. Mohamed, R. Dillert, and D. Bahnemann, "Kinetics and mechanisms of charge transfer processes in photocatalytic systems: a review," J. Photochem. Photobiol. A, vol. 13, no. 4, pp. 263-276, 2012.
[107] Y.-H. Chiu, K.-D. Chang, and Y.-J. Hsu, "Plasmon-mediated charge dynamics and photoactivity enhancement for $\mathrm{Au}$ decorated ZnO nanocrystals," J. Mater. Chem. A, vol. 6, no. 10, pp. 4286-4296, 2018.

[108] J. N. Tiwari, A. N. Singh, S. Sultan, and K. S. Kim, "Recent advancement of $\mathrm{p}$ - and d-block elements, single atoms, and graphene-based photoelectrochemical electrodes for water splitting," Adv. Energy Mater., vol. 10, no. 24, p. 2000280, 2020.

[109] C. Gao, J. Low, R. Long, T. Kong, J. Zhu, and Y. Xiong, "Heterogeneous single-atom photocatalysts: fundamentals and applications," Chem. Rev., 2020. https://doi.org/10.1021/ acs.chemrev.9b00840. 